\title{
Mucoadhesive Polymers for Oral Transmucosal Drug Delivery: A Review
}

\author{
Jose' Bagan $^{1, *}$, Carlo Paderni ${ }^{2}$, Nicoletta Termine $^{2}$, Giuseppina Campisi $^{2}$, Lucio Lo Russo $^{3}$, Domenico \\ Compilato $^{2}$ and Olga Di Fede ${ }^{2}$
}

\author{
${ }^{1}$ Service of Stomatology, University General Hospital of Valencia, Valencia, Spain; ${ }^{2}$ Sector of Oral Medicine "V. Margiotta", Section \\ of Odontostomatologic Sciences, Department of Surgical and Oncological Disciplines, University of Palermo, Palermo, Italy; \\ ${ }^{3}$ Department of Surgical and Oncological Disciplines, University of Foggia, Foggia, Italy
}

\begin{abstract}
The oral mucosa offers an interesting site for the application of dosage forms that release drugs within/throughout the oral mucosa, by assuring a high drug bioavailability for topic and systemic effects. However, the relative permeability of the oral mucosa and the washing effect related to the oral fluids and mechanical stresses must be considered in the formulation of oral dosage forms. Since a sustained drug release can be guaranteed only if dosage forms remain in contact with the oral site of absorption/application for a prolonged time, the development of mucoadhesive dosage forms is mandatory. The mucoadhesion is a complex phenomenon and the mucoadhesive bond consists of two different parts, the mucoadhesive polymers and the mucous substrate. In addition to factors related to the oral mucosa and oral environment features, the physical-chemical characteristics of mucoadhesive polymers must be also considered as factors influencing the mucoadhesive bonds. While it is not possible to modify the mucosal features or it is possible to modify or inhibit only in part certain mucosal processes, the knowledge of polymer properties influencing mucoadhesive bonds allows to modify or to control these properties in developing increasingly effective mucoadhesive systems. The aims of this review are to discuss the several mechanisms and factors behind the phenomenon of mucoadhesion with particular reference to the features of the oral environment, oral mucosa, and polymeric compounds influencing mucoadhesion process. Finally, a brief mention to the main mucoadhesive dosage forms designed for oral transmucosal drug delivery is made.
\end{abstract}

Keywords: Mucoadhesion, oral transmucosal drug delivery, dosage form, drug controlled-release, mucoadhesive polymers, oral mucosa, mucosal permeability.

\section{INTRODUCTION}

The ultra-structural features of the oral mucosa have attracted increasing attention due to its potential use for the systemically/topically delivery of biologically-active drugs, which possess high pharmacological efficacy with site-specificity; to date, these drugs cannot be administrated through an effective, safe, and noninvasive route. Oral transmucosal drug delivery is growing as a feasible alternative to conventional (peroral and parenteral) routes as it offers many advantages. Unlike the peroral route, it avoids the gastric hydrolysis and hepatic first-pass effect and hence it provides an improved bioavailability, lower drug doses and less dose-related side effects [1,2]. Since the parenteral route is more invasive, often requiring numerous injections due to the short half-life of certain drugs and is not free from complications as anaphylaxis, blood extravasation and infections, oral transmucosal drug delivery ensures a safe, not invasive route with a better patient compliance, especially during medium- and long-term chronic therapy. In addition, the oral mucosa offers some clear advantages over other transmucosal (ocular, nasal, pulmonary, rectal and vaginal) and transdermal administration routes [3]. In fact, among all the transmucosal sites, the oral mucosa is more easily accessible and is highly vascularized, allowing a direct access to the systemic circulation by-passing the liver first-pass effect with consequent high bioavailability and acceptability by the patient [4]. Moreover, as being characterized by a rapid cellular turnover, the oral mucosa is less susceptible to damage or irritation potentially related to the drug or the excipients loaded in the dosage forms [5]. Finally, the relative absence of peptidases and/or the possibilities to use enzyme inhibitors as excipients in the dosage forms makes the oral mucosa a promising route for the systemic delivery of macromolecular drugs (peptides and proteins) [6]. Nevertheless, the oral transmucosal route has some disadvantages mainly related to the low

*Address correspondence to this author at the Professor of Oral MedicineValencia University. Chairman Service of Stomatology. University General Hospital. Valencia. Avda de Tres Cruces s/n 46014 - Valencia, Spain; E-mail: bagan@uv.es permeability of the mucosal membrane and to the physiological mechanisms, as washing effect or saliva and mechanical stresses, which cause short retention times of the conventional dosage forms since they are quickly removed from the site of application/ absorption [7].

These limitations can be overcome by developing of bioadhesive dosage forms. Various administration routes, such as ocular, nasal, buccal and gingival, gastrointestinal, vaginal and rectal, are based on mucoadhesive drug delivery systems [8].

The advantages associated with the use of mucoadhesives in drug delivery include: i) an intimate and prolonged contact with the site of absorption for an increased retention time without interfering with the physiological activities such as eating, drinking and talking; ii) an improved drug bioavailability; iii) a reduced administration frequency; iv) a simplified administration of a dosage form and v) termination of a therapy as well as the possibility of targeting particular body sites and tissues [9]. The mucoadhesion is achieved through the use of special polymers that allow the binding to the mucin layer of biological membranes. These polymers should have some basic requirements, such as anionic hydrophilia with hydrogen groups, a sufficient flexibility and wetting and spreading capability to the mucus network surface and to the tissues crevices [10].

In addition, chemical permeation enhancers, enzyme inhibitors or $\mathrm{pH}$ modifiers may be included as excipients in several dosage forms in order to warrant the release of a correct therapeutic dose of medication, either locally or systemically, at a fixed rate in a specific site of action/absorption [11]. Finally, during the formulation design of new delivery systems, the possibility, by combining two or more mucoadhesive polymers, to formulate devices for issuing multi-directional or unidirectional drug release, depending on therapeutic needs, must also be considered [12].

The aims of this review are to discuss the several mechanisms and factors behind the phenomenon of mucoadhesion with particular reference to the features of the oral environment, oral mucosa, and polymeric compounds influencing mucoadhesion process. Fi- 
nally, a brief mention to the main mucoadhesive dosage forms designed for oral transmucosal drug delivery is made.

\section{ORAL MUCOSA AND ORAL ENVIRONMENT}

Although extensively discussed in other publications [12-16], the knowledge of anatomical, histological and physiological features of the oral mucosa as well as those of the main factors belonging to the oral environment (i.e. mucus, saliva) which may affect the mechanisms of bioadhesion on mucosal surface must be considered a starting point to better understand the phenomenon of mucoadhesion.

\subsection{Oral Mucosa: Histology, Physiology and Permeability Fea- tures}

The oral cavity must be considered as a unique structure that extends from vermilion of the lips anteriorly, to the isthmus of the mouth posteriorly and includes the lips, cheeks, tongue, hard and soft palate and the floor of the mouth. The oral cavity, like other body cavities that communicate with the external world, is covered by a biological membrane called oral mucosa, coated by mucus or serous secretions.

The oral mucosa has a total surface area of about $200 \mathrm{~cm}^{2}$ and shows differences in structure, thickness and blood flow depending on their location within the oral cavity [17]. Both histologically and functionally it consists of two layers, one of mesodermal origin (lamina propria) and the epithelial one, connected by a proteinaceous fibrous extracellular matrix thickness called basal lamina or basement membrane [18] (Fig. 1a). This structure constitutes a distinct layer from the epithelial and connective tissues, but is closely linked to them; in fact it provides a mechanical support to the overlying epithelium and permits its connection to the underlying lamina propria. The basement membrane with a thickness of about $1-2 \mu \mathrm{m}$ acts as barrier to permeability only marginally, limiting the diffusion of certain molecules (such as complexes) from and to the epithelium [19]. Furthermore, the surface charge of its molecules may impede and/or limit the penetration of lipophilic molecules which have just passed the epithelial layer relatively easily [20].

The lamina propria provides many of the mechanical properties of the oral mucosa and the blood supply essential for the epithelial tropism; it also allows the passage of molecules (included the drugs) in the systemic circulation (see below), one of the main aspect in the oral drug delivery. Since its structure is insufficiently dense it not usually acts as a barrier also to relatively large molecules; furthermore, its hydrated matrix may facilitate the passage of hydrophilic compounds [4].

The stratified squamous epithelium consists of differentiating layers of cells (keratinocytes) which change in size, shape, and
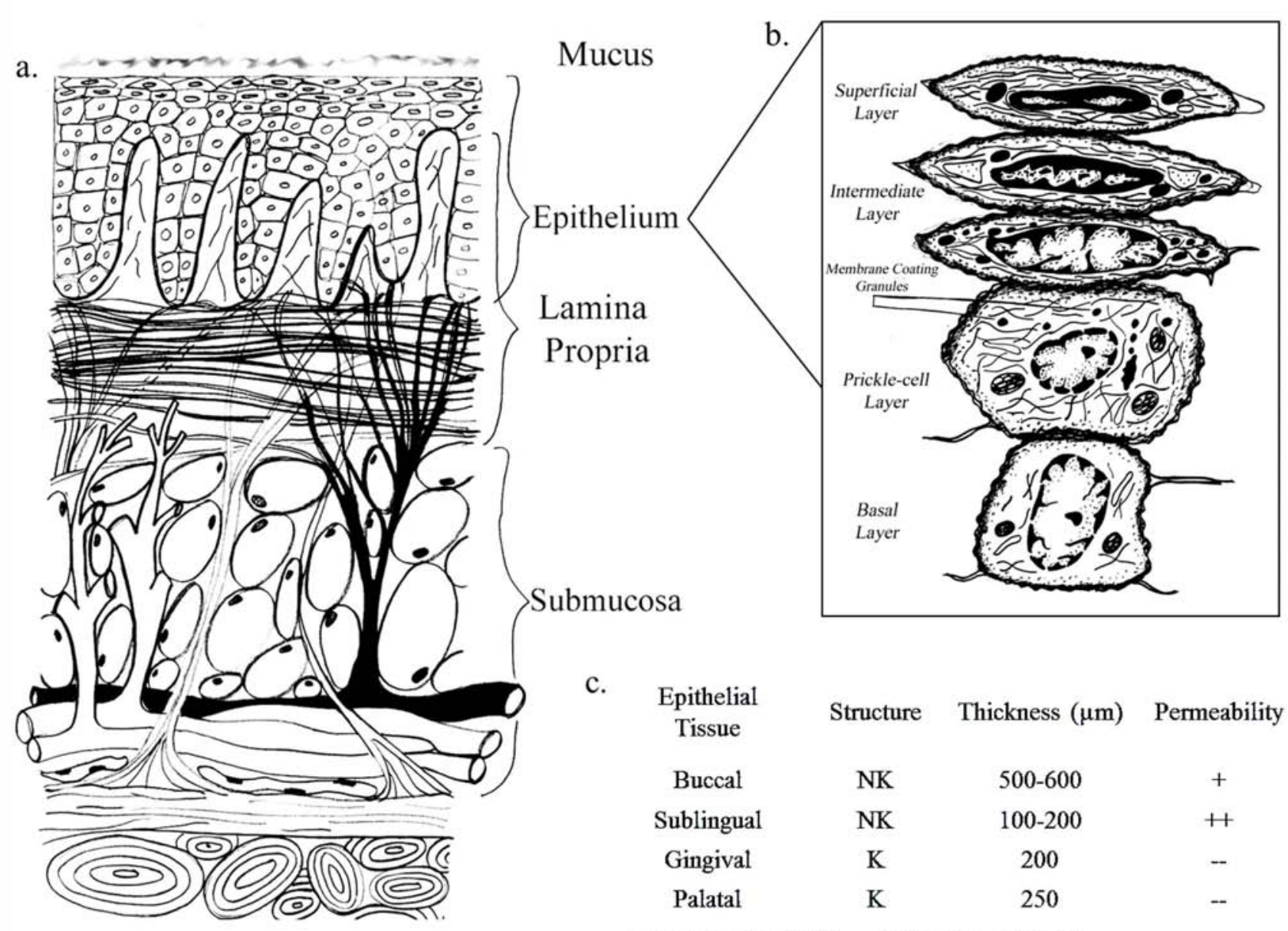

c.

$\begin{array}{cccc}\begin{array}{c}\text { Epithelial } \\ \text { Tissue }\end{array} & \text { Structure } & \text { Thickness }(\mu \mathrm{m}) & \text { Permeability } \\ \text { Buccal } & \text { NK } & 500-600 & + \\ \text { Sublingual } & \text { NK } & 100-200 & + \\ \text { Gingival } & \text { K } & 200 & - \\ \text { Palatal } & \text { K } & 250 & - \\ \text { ++ means "very suitable"; - - means "least suitable"; } & \\ \text { NK means "Non-Keratinized"; K means "Keratinized". } & \end{array}$

Fig. (1). a) A schematic representation of the structure of the oral mucosa with special details (b) for the oral epithelium layers. MCGs become apparent in the upper part of the spinous layer $(\mathbf{b})$; $\mathbf{c})$ this table shows differences in the degree of keratinization, thickness and permeability features between the oral different sites. 
content as they travel from the basal region to the superficial region, where the cells are shed (Fig. 1b). The epithelium of the oral mucosa is about 40-50 cell layers thick [15], even if the thickness of oral mucosa varies depending on the site: the buccal mucosa and the dorsal tongue measures 500-800 $\mu \mathrm{m}$, while the epithelial thickness of the hard and soft palates, the floor of the mouth, the ventral tongue, and the gingivae are about 100-300 $\mu \mathrm{m}$ [15] (Fig. 1c). Oral squamous stratified epithelium is divided into non-keratinized and keratinized epithelium. The differentiation processes that occur in keratinized and non-keratinized epithelia differ significantly, and this results in either the presence or absence of a cornified surface layer [21].

The structure of the oral mucosa varies according to functional adaptations between the different regions of the oral cavity. It is noteworthy that there are three different types of oral mucosa within the oral cavity [22-25]: masticatory mucosa (i.e. gingivae and hard palate), specialized mucosa (i.e. dorsum of tongue) and lining mucosa (e.g. buccal mucosa and floor of mouth). From measurements made by Collins and Dawes [17], these represent approximately $25 \%, 15 \%$ and $60 \%$ of the oral mucosa, respectively. The oral mucosa subjected to mechanical stress such as gingivae and hard palate is keratinized similar to the epidermis. The epithelium of the lining mucosa covers the remaining regions, except the dorsal surface of the tongue, and is a non-keratinized one.

As discussed above, the oral mucosa is characterized by highly compacted epithelial cells, whose primary functions are to protect the underlying tissues against fluid loss and from chemical and mechanical damages [19]. Nevertheless, it is well known as the oral mucosa is 4-4000 times more permeable than the skin [26].

The oral mucosal tissue produce a large amount of extracellular material, useful for the epithelial elasticity, lubrication and wettability of the cell epithelial surface, for the regulation of its moisture content and as a permeability barrier. The cell membrane of outer cell layers of non-keratinized epithelia contains lipids as phospholipids, cholesterol sulphate, ceramide, glucosphingolipid and glycosylceramides which act as a barrier to hydrophilic molecules [27, 28]. However, the presence of lipids and cytokeratins in the superficial keratinocytes of the non-keratinized epithelia is much less marked than in the keratinized ones, making the lining mucosa much more permeable, especially to water and hydrophilic molecules, and so more suitable for systemic drug delivery. Whilst the outer layer of the epithelium is liphophilic, the interior content of the cells is hydrophilic; hence, to obtain an efficient drug delivery, drug formulations must be designed in such a way to overcome this double barrier, one hydrophobic and one hydrophilic in nature, to pass and diffuse through the epithelial tissue and reach the lamina propria $[29,30]$.

Furthermore, it is important to underline that the main "barrier region" to penetration of molecules across the oral epithelium is such due to the intercellular material originated from the "membrane coating granules" (MCGs) [31, 32]. They have been found in both non-keratinized and keratinized epithelia, highlighting as the keratinisation, alone, cannot act as the main factor against the penetration of molecules [33, 34]. The MCGs are small cytoplasmic organelles mainly produced by the Malpighian cells. Their content, rich in lipids and glycolipids, is discharged in the extracellular spaces covering and linking the cells of the stratum spinosum, which contains not flattened cells closely held together by desmosomes at various stages of differentiation [35] (Fig. 1b) Here, the content of MCGs also acts as a barrier to permeation of various molecules [36].

Another barrier to drug permeability across the oral epithelium is represented by enzymatic degradation of peptides and proteins. In addition to salivary enzymes (see below), several proteolytic enzymes are present both within the cell cytoplasm and in the extracellular matrix [37]. The extracellular enzymes are mainly repre- sented by aminopeptidases (aminopeptidase A and N - plasma membrane bound peptidase) and protease; whilst some intracellular peptidase (aminopetidase B - cytosolic peptidase) provide the hydrolysis of particular smaller peptides, which penetrate within the epithelial cells, in to free amino acids [38]. Unlike the enzymatic barrier existing in the small intestine, oral mucosa is less rich of peptidase linked to the cell membrane [6], so the peptide drug metabolism occurs mainly in the intracellular environment where they are located most of the endopeptidase. It would seem that the enzymatic barrier is able to hydrolyse only the drugs that permeate through an intracellular pathway, while, due to the low extracellular proteolytic activity of the oral epithelium, drugs that follow a paracellular route of absorption would be able to avoid this degradation $[6,12]$.

Since proteolytic enzymes are ubiquitous, the absorption of peptide drugs and the action of mucoadhesive polymers in their intact forms are virtually impossible, and thus, the use of enzyme inhibitors in the dosage forms is needful $[6,12,39]$.

Despite the above mentioned factors which may interfere with the permeability, but as will be shown in this review they can be overcome, there are some important aspects which allow to consider the oral mucosa as an innovative site for transmucosal drug delivery. Beyond its easy and not invasive accessibility, the two main factors for oral drug delivery are the turnover time of epithelial cells and the vascularisation of the lamina propria. The rate of turnover is the time for a cell to divide and pass through the entire epithelium and, for oral epithelium, falls between those for skin (34 days) and intestine (4 days) and it has been generically estimated at 5-6 days [4]. The rate of the epithelial cell proliferation depends on different patterns of epithelial maturation: in general, the rate is higher for cells in thin non-keratinized regions, such as floor of mouth and ventral surface of tongue than for thicker keratinized regions, such as palate and gingiva [40]. The high turnover rate is an important issue that affects drug absorption, by continually changing permeability features, demanding long-term bioadhesion of dosage forms for prolonged drug delivery; furthermore, it is important to underline that the high turnover rate makes the oral mucosa able to promptly reacting to any external insult. Compared to other transmucosal sites, oral mucosa is less susceptible to injury or damage potentially related to the drug or the excipients loaded into the transmucosal dosage forms [41].

The other important factor is the vascularisation of the oral mucosa. Thanks to a rich arterial blood supply derived from the external carotid artery and its secondary vessels, the oral mucosa, although with some differences among the various sites, is a structure highly vascularised. This aspect is one of the main factors for the drug delivery efficiency through the oral cavity. In fact, although the entire surface area of the oral mucosa is smaller than that of the skin $\left(20.000 \mathrm{~cm}^{2}\right)$ and gastrointestinal tract $(350.000$ $\mathrm{cm}^{2}$ ), its high vascularization and the relatively fast blood flow (i.e. $2.4 \mathrm{ml} / \mathrm{min} / \mathrm{cm}^{2}$ for the buccal mucosa) facilitates the passive diffusion of drug molecules across the mucosa and their direct access to the systemic circulation via venous capillaries which reach the internal jugular vein, by-passing the gastrointestinal tract and the hepatic first-pass metabolism with consequent high drug bioavailability.

\subsection{Absorption Pathways}

Permeability measurements have suggested that different substances may permeate oral epithelium at different rates, depending on the chemical nature of the molecule and the histological features of the tissue being traversed. There are considerable regional differences in the permeability pattern in oral mucosa. In general, the permeability of oral mucosa decreases gradually from the sublingual through to the buccal and palatal mucosa [12]. This rank order is related to the relative thickness and degree of keratinization between these regions: sublingual mucosa is relatively thin and non- 
keratinized, the buccal thicker is non-keratinized, and the palatal is intermediate as regards thickness but keratinized [36]. Compounds with different chemical properties penetrate the "barrier region" by different routes. Substances can be transported across the mucosal membrane by passive diffusion, carrier-mediated active transport or endocytosis. Two main pathways seem to be implicated in passive diffusion across membranous tissues: intra-cellular (or transcellular) pathway and inter-cellular (or paracellular) pathway. A single drug can permeate through the oral mucosa using both routes simultaneously but the route offering the least penetration resistance is usually preferred, depending on the physicochemical properties of the drugs (e.g. size, lipophilia, hydrogen bond potential, charge and conformation) [38]. It should be emphasized that the oral mucosa is both hydrophilic and lipophilic in nature. While portions of the intercellular spaces and cytoplasm are hydrophilic, thereby providing a permeability barrier to lipophilic compounds due to their low solubility, the cell membrane and the intercellular lipids are lipophilic and, given their low partition coefficient, they provide a permeability barrier to hydrophilic drugs. Although a carrier-mediated transport of monocarboxylic acids from rabbit oral mucosa has been reported [44], these systems have not been fully described and further investigations are warranted.

The process of absorption of a drug across the oral mucosa occurs principally by a process of passive diffusion. Therefore, considering the oral mucosa as a hydrophobic membrane, Fick's first law equation can be used to describe the process of absorption of a drug [42]. By analysing this equation, there are drug and oral mucosa not modifiable parameters, such as diffusion coefficients, the partition coefficient, the tissue thickness and adjustable parameters such as surface area available absorption, retention time and concentration of the drug, which are features that can be modified by the formulation of the dosage form.

\subsection{Oral Environment}

In addition to the intrinsic features of the oral mucosa, two other important factors, as saliva and mucus, belonging to the oral environment, play an important role both in transmucosal drug delivery and in mucoadhesion. A special attention will be focused on mucus and mucins as the knowledge of their composition, structure and function is crucial for the mechanisms of bioadhesive controlled drug release.

\subsubsection{Saliva}

Saliva is a fluid mainly composed of water (99.5\%), inorganic $(0.2 \%)$ and organic substances $(0.3 \%)$ [43] which continuously wets the whole surface of the oral mucosa creating a thin coating of about $70 \mu \mathrm{m}$ [17].

The presence of saliva facilitates the dissolution of the drug from the dosage form, but at the same time, when it is swallowed, can contribute to its removal from the site of action/absorption. In addition, the drug released by the delivery device is not uniformly distributed within the saliva so that some areas of the oral cavity could not receive therapeutic levels of the drug [44]. The constant flow of saliva in the mouth make difficult the application of dosage forms able to stay in close contact with the mucosa for a long period of time.

On the other hand, the continuous hydration of the mucus membrane, due to saliva, can greatly facilitate the drug absorption improving the mucoadhesion of mucoadhesive delivery systems [6].

The optimal hydration and moisture status of the oral mucosa is guaranteed by the salivary proteins and in particular to some mucin glycoproteins. The most important salivary mucin is called MG1 [45] whose role are: to maintain hydration, to provide lubrication, to concentrate protective molecules such as secretory immunoglobulins, and to limit the attachment of microorganisms.
In general, mucins are important not only because provides the oral mucosa wettability but mainly for their fundamental role in mucoadhesion of the dosage forms (see below).

Finally, it must be considered that saliva contains moderate levels of some enzymes as esterases, carbohydrases and phosphatases that may degrade certain drugs and adhesion polymers, participating in the realization of the enzymatic barrier.

\subsubsection{Mucus}

Mucus is a complex viscous adherent secretion lining the epithelial surfaces of the eyes, ears, nose, respiratory, reproductive and gastrointestinal tracts, included the oral cavity $[46,47]$.

Mucus is produced by mucous cells (usually the goblet cells), which are common constituents of the lining epithelia of organs and apparatuses communicating directly and indirectly with the external environment. Instead, in the oral cavity, most of mucus (about $70 \%$ ), fundamental to maintain the mucin layer over the oral mucosa, is produced by mucus secreting cells belonging to the sublingual and minor salivary glands [29, 44, 48].

Mucus is primarily composed of water (90\%-98\%) and mucins forming a viscoelastic mixture of (in a smaller proportion, $-<1 \%$ ) proteins, immunoglobulins (secretory IgA), enzymes (lysozyme and lactoferrin), lipids, mucopolysaccharides, nucleic acids, cellular debris and various ionic species [49]

Mucins are hydrophilic and asymmetric glycoproteins with a high molecular weight; they are composed by a single chain protein-based backbone (composed by amino-acids as serine, threonine and proline) from which branch off many large oligosaccharidebased chains (composed by $\mathrm{N}$-acetylgalactosamine, $\mathrm{N}$-acetylglucosamine, galactose, fucose and $\mathrm{N}$-acetylneuramic acid or sialic acid). The protein core is heavily glycosylated for about its $63 \%$ by oligosaccharide chains and shows one o more terminal peptide regions where there is little o none glycosylation.

Other than carbohydrates and proteins that constitute the mucin structure for the $70 \%-80 \%$ and $12 \%-25 \%$, respectively, up to $5 \%$ of ester sulphate have been founded [50,51].

Each mucin molecule is characterized by an open structure, linear and non-linear, organized according a random criteria. Thanks to the establishment of both intermolecular non-covalent and disulphide bonds, the mucin glycoproteins bind to each other forming a highly entangled network of macromolecules that represent the central structure of the mucus and is responsible for its rheological properties [49]. The heavily glycosylation of mucins related to their dense oligosaccharide-based coating makes mucin network able to retain water, imparting a gel-like property to mucus and a resistance to proteolysis [29].

When the environmental $\mathrm{pH}$ is near neutral, as in the oral cavity in which it oscillates from 6.2 to 7.4 , the presence of sulphate groups associated to carboxylate groups (sialic acid) at the terminus of some sugar units renders mucins to be molecules with a negative charge and then they behave as an anionic polyelectrolyte; this may play a role in mucoadhesion $[49,52]$. Hence, at physiological $\mathrm{pH}$, mucus can form a highly cohesive gel structure that binds to the epithelial surface, forming a gelatinous layer [53] which associated to its resistance to proteolysis may contribute to maintain the barrier properties of oral mucosa [25].

Because of the numerous anionic and cationic functional groups of mucins, the electronically charged molecules may interact, by means of electrostatic attractions, hydrogen bonds or hydrophobic interactions, with some environmental molecules, included drugs, obstructing their transport throughout the epithelium $[6,54]$.

Mucus is a dynamic system, generated continuously by mucus cells, having a short clearance period, a relatively fast turnover time (that influence mucoadhesion) and whose secretion may be stimulated by toxic and irritating stimuli in order to form a thick layer and so to remove irritants from the epithelium [52]. However, it is 
important to underline that the barrier determined by the mucus layer is negligible compared to other barriers that molecules encounter during their passage through the oral mucosa [6]. Mucus layer is an efficient semi-permeable barrier system allowing the diffusion of selected small molecules (water, nutrients) and ions; whilst it remains impermeable to the most pathogenic microorganisms and also to the diffusion of many large drug molecules and nanomedicines [54].

Despite the possibility that the mucus layer interferes with the absorption of drugs, its presence can be beneficial for preparing bioadhesive transmucosal drug delivery systems.

\section{DRUG DELIVERY VIA THE ORAL MUCOSA}

Considering the above described features of the oral mucosa and the complexity of the oral environment, it is easily understood that it is feasible using the oral mucosa as a site for oral transmucosal delivery, but, at the same time, there are many parameters to consider for a successful formulation of oral transmucosal dosage systems.

Briefly, drug delivery via the oral mucosa can be subdivided into two different approaches: drug delivery via the keratinized mucosae and drug delivery via the non-keratinized mucosae (Fig. 2). The selection of an approach over another mainly depends on regional differences in terms of anatomical and permeability features, which exist among these oral mucosal sites [5]. The keratinized mucosae, such as gingival and hard palatal mucosae, are not still considered a valid site for systemic administration of drugs and they should be considered as useful sites for local drug delivery in the treatment of oral diseases with gingival or palatal location. In particular, rationale behind gingival drug delivery is that concentrated amounts of active medications can be delivered to the precise site of the disease process with minimal systemic uptake of the medication [55]. Such kind of devices could be useful adjuncts to conventional mechanical therapy and are related to low side effects and drug interactions.

Drug delivery via the not keratinized mucosae can be subdivided into two approaches: sublingual drug delivery, which is systemic delivery of drugs across mucosa lining the floor of mouth; buccal drug delivery, mainly via the buccal mucosa lining the cheeks, includes systemic and/or local delivery. The sublingual mucosa is more permeable and thinner than the buccal mucosa, making it a feasible site if a rapid onset is desired [15]. Thus, the sublingual route is generally used for the systemic delivery of drugs in the treatment of acute disorders. The buccal mucosa is considerably less permeable than sublingual mucosa and it is unable to provide the rapid onset of absorption observed with sublingual administration [4]. Furthermore, the lower permeability of this region and the presence of smooth muscle and relatively immobile mucosa make buccal mucosa a preferred route for the systemic treatment of chronic disorders when the sustained release of systemically-acting drugs, by means of mucoadhesive delivery systems, is required, thereby overcoming the drawbacks when administered by conventional routes [56].

Oral local drug delivery is a more efficient drug delivery approach than systemic delivery for the treatment of oral conditions. The reason for the large interest in the local treatment of the oral cavity diseases is a result of their being amongst the most prevalent in humankind. Several different types of oral cavity disorders exist, such as oral candidiasis, gingivitis, xerostomia, dental caries, acute and chronic oral lesions which could be treated locally without the need for ingestion and systemic distribution of drugs. Traditional treatments of oral diseases are extremely costly in most industrialized countries, according to the World Health Organization. Many oral diseases are chronic and, hence, require chronic treatment regimens [57]. Local drug delivery provides a more targeted route of administration as smaller amounts of drug can be easily targeted to the not healthy site, thereby reducing side effects. On the basis of these considerations, local drug delivery should be considered a delivery route appropriate for drugs exhibiting high therapeutic potency as relatively small quantities of drugs can be delivered directly onto the oral lesion [58].

Unfortunately, when administered in both local and systemic within/throughout the oral mucosa, conventional dosage forms have not been effective in ensuring adequate therapeutic levels of drugs at the site of action/absorption. The main disadvantage is the low bioavailability depending on the physiological removal mechanisms

\section{Drug Delivery via the oral mucosae}

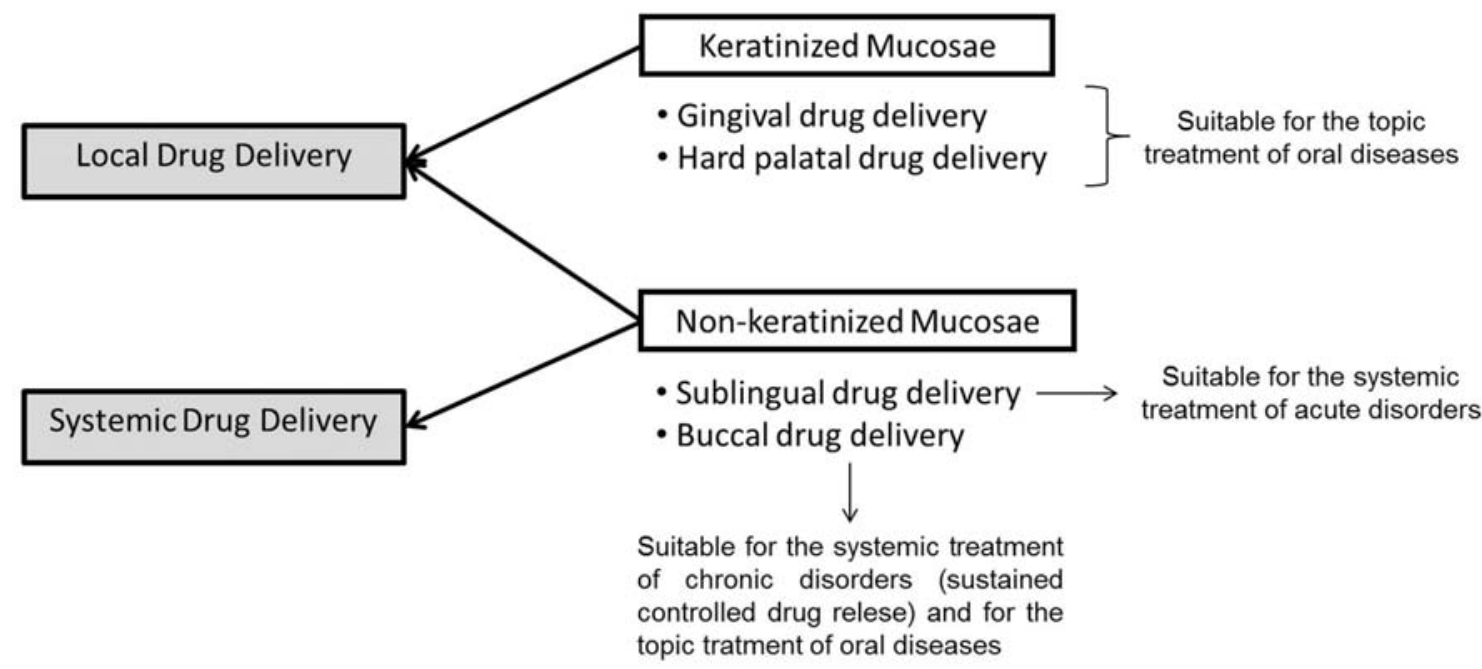

Fig. (2). Drug delivery via the oral mucosa may occur in different ways according to the degree of keratinization of the oral sites. Generally, keratinized areas offer a certain resistance to the drug absorption and thus they can be used only for the topical treatment of oral diseases. The not keratinized sites instead can be used also for the systemic release of drug, whose more or less onset of action depends on the degree of vascularization of the oral site of absorption. 
of the oral cavity (washing effect of saliva and mechanical stress). These dosage forms are constantly washed away, resulting in a too short retention time, unpredictable distribution of the drug on the site of action/absorption and an initial burst effect followed by a rapid decrease in concentrations to below therapeutic levels [12].

To overcome these problems, dosage forms should have in their formulation:

1. Mucoadhesive polymers, in order to provide an intimate and prolonged contact with the absorption site;

2. chemical penetration enhancers, in order to improve drug permeation across oral mucosa or drug penetration into the deepest layers of the epithelium, according to the therapeutic needs (systemic or local drug delivery);

3. enzymatic inhibitors, in order to eventually protect drugs from the enzymatic degradation.

For these reasons, new "attached" (better defined as adhesive) drug delivery systems for the local drug delivery have been developed [59]. Recent research on polymers with mucoadhesive properties has led to the development of several buccal delivery systems able to maintain a steady release of drug in the systemic circulation thanks to a closed contact with the mucosal membrane, resulting in high concentration in a local area and high drug flux through the mucosa [11-15, 33-41]. Because the transient spikes in drug concentration, typical in a daily multiple-dose regimen, are not present with these delivery systems, the risk of toxic side-effects is decreased [57].

\section{ADHESION PROCESS}

The term adhesion indicates the fixing of two surfaces together. If the environment, in which this union takes place, is biological in nature, the term "bioadhesion" should be preferred. In pharmaceutical science, the bioadhesion refers to the adhesion of a polymeric delivery system to a biological surface [60]. Instead, the term "mucoadhesion" must be preferred if an intimate contact between the mucosal surface, covered with mucus, and a polymer occurs [61]. The mucoadhesion is a complex phenomenon and the mechanisms by which a polymer adheres to the mucosal surface are not fully understood.

The term polymer indicates long macromolecules consisting of structural subunits and repeating subunits linked by covalent bonds. These subunits, called monomers, are low-medium molecular weight molecules that connect with each other during polymerization process, giving rise to macromolecules with new chemical and physical characteristics [29]. The adhesive polymers represent a large family of molecules which are generally used in the formulation of mucoadhesive dosage forms in order to form an adhesive bond with the biological structures thanks to the mucoadhesive features of these macromolecules.

To explain the mucoadhesion phenomenon, five different theories have been proposed, but it is likely that all these theories must be considered as different phases of a single process characterized by multiple steps of interaction between the two substrates, rather than as individual and different theories [8, 49, 52].

\subsection{Absorption Theory}

This theory states that the adhesion is the result of the formation of interfacial chemical (primary and secondary) bonds between the mucoadhesive polymer and the mucus substrate. The secondary chemical bonds such as hydrogen bonds and electrostatic interactions are the most desirable in the formulation of adhesive systems, since they have the advantage of being semi-permanent, while the primary chemical bonds, as covalent, metallic and ionic, may cause irreversible damage of the due to their permanent features [62].

\subsection{Electronic Theory}

This theory is based on the transfer of electrons due to the different electrical properties of the mucus and the mucoadhesive polymer. The electron transfer involves the formation of a double layer of charges and consequently electrostatic attractive forces and an interdiffusion layer between the two surfaces with opposite charges. It is likely that this theory is more relevant in adhesion involving polymer and metal substrates. Controversial opinions about this theory consider the electrostatic forces only the result of an high bond strength rather than a crucial factor in the formation of the adhesive bond [63]

\subsection{Fracture Theory}

This theory connects the force required to separate the polymeric compound from the substrate with the mucoadhesive bond strength. The energy required to break this bond was found to be greater as the chains of the polymer network are longer and as the cross-linking degree of the mucoadhesive system are lower. This theory is particularly considered useful to calculate the strength of adhesive bond when mucoadhesive solid and rigid materials are involved [60].

\subsection{Wetting Theory}

This theory is based on the penetration of the adhesive polymers through the mucosal surface irregularities and their subsequent anchoring. This theory is mainly applicable to liquid or semisolid mucoadhesive systems and basically may be considered as a measure of the capability of mucoadhesive systems to wet the mucosal surfaces. The adhesive performance of a liquid or semi-liquid adhesive system depends on its wettability. The wettability can be defined as the ability of a viscous liquid to maintain contact with a solid surface, resulting from intermolecular interactions when the two are brought together. The degree of wetting (wettability) is determined by a force balance between adhesive and cohesive forces. Regardless of the amount of wetting, the shape of a liquid drop on the mucosal surface is approximately a truncated sphere. Adhesive forces cause a liquid drop to spread across the surface. Cohesive forces within the liquid system cause the drop to ball up and avoid contact with the surface. The contact angle $(\theta)$, is the angle at which the liquid-vapour interface meets the solid-liquid interface. The contact angle is determined by the resultant between adhesive and cohesive forces. As the tendency of a drop to spread out over the mucosal surface increases, the contact angle decreases. Thus, the contact angle provides an inverse measure of wettability. The polymeric adhesive systems that have structural features and functional groups similar to the mucus substrate, have a greater miscibility, and thus an higher degree of spreadability on mucosal surfaces $[63,64]$.

\subsection{Diffusion Theory}

The theory is based on the concentration gradient- and timedependent penetration of the polymer chain of the macromolecules in the glycoprotein network of the mucus. This two-way diffusion process involves the formation of a layer of interpenetration and the strength of the adhesive bond depends on its extension. It is reported that an effective adhesion is usually achieved when the interprenetration layer thickness reaches about $0.2-0.5 \mu \mathrm{m}$. The extent of this layer depends on various factors such as concentration gradient, molecular weight of adhesive macromolecules, their hydrodynamic size, their mobility and flexibility. The length of the polymer chains is also an important factor: long polymer chains are more able to disseminate and penetrate mucus substrate and it has been reported that a chain length of at least $100,000 \mathrm{kDa}$ is necessary to obtain an interprenetration degree suitable for the formation of the adhesive bond; on the other hand, an excessive cross-linking degree between the polymer chains could result in a reduced mobil- 
ity and therefore decrease the extent of interprenetration layer and strength of the adhesive bond [49].

The depth of this layer also depends on the contact time referred as the retention time of the mucoadhesive dosage form on the mucosal surface in order to ensure an adequate exposure of contact between the surfaces of both polymers. Recently, it was shown that the temperature is another important environmental factor in this process.

A key factor, in obtaining the maximum interdiffusion between both polymeric networks and the best strength during the formation of the adhesive bond, is that both systems should be miscible with each other since they should have similar solubility parameters and diffusion coefficients [62].

As above mentioned, none of these theories probably comprehensively explains the complex phenomenon of mucoadhesion since it is probably derived from the combination of different mechanisms. Therefore, it is preferable to divide the process of mucoadhesive bond formation in two main phases. During the first phase (or contact stage), the mucoadhesive dosage form wets, swells and expands by spreading in the mucus network irregularities (wetting theory), contributing to the formation of a double layer of mechanical interpenetration between the polymer and the mucus layer (diffusion theory). The second phase (or consolidation stage) is the result of chemical interactions i.e. covalent and ionic bonds, hydrogen bonds, electrostatic interactions and van der Waals forces between the two substrates (absorption and electronic theory) [49].

\subsection{Test Methods to Study Mucoadhesion}

To date, there are no standardized test methods specifically designed for the mucoadhesion analysis. Researchers are continuing to develop new methods for evaluating the performance of individual adhesive polymers and/or mucoadhesive properties of different dosage forms. However, because of the lack of one or more standardized techniques, it is difficult to make a direct comparison of data obtained by different research groups. So far, most of the information on bioadhesive materials derived from in vitro methods, while in vivo techniques are considered as final tests for those that seemed promising as bioadhesives during the initial screening by using in vitro techniques [52].

In vitro tests are probably the most common methods for determining the bioadhesive performances. Several techniques currently in use ranging from simple measurements of the detachment force to much more complex experiments have been described in the literature. The most common in vitro method to evaluate the mucoadhesive potential are reported in Table $\mathbf{1}$.

\subsection{Factor that Influence Mucoadhesion in the Oral Cavity}

The mucoadhesion process in the oral cavity is closely related both to the molecular features of the bioadhesive polymers and to the medium and the environment in which they are inserted.

As seen in the previous paragraphs of this paper, saliva and mucin are the main biological factors, belonging to the oral cavity which may affect, both positively and negatively, the mucoadhesion.

The interface between the bioadhesive polymer and the oral epithelium is provided by mucus which viscosity, degree of entanglement, and water content may affect the bioadhesion process, influencing the extent of interaction between the polymer and the mucosal substrate. The turnover rate of mucus and the solubility or insolubility of the polymers in water determines the residence time of the bioadhesive dosage form at the application/absorption site. The oral $\mathrm{pH}$ may also influence bioadhesion, altering the superficial charge of mucus and the ionization of certain adhesive polymers. The mechanical stresses, to which the oral tissues are subjected, during eating, drinking, talking and swallowing which also continue involuntarily during the night, reduce the contact time of the dosage form with the mucosal surface, and hence affect negatively the bioadhesion; these removal forces should be considered during the formulation of mucoadhesive dosage forms. Furthermore, it is possible that tissue modifications induced by certain diseases may change the retention bioadhesive properties.

The most important polymer-related factors affecting their mucoadhesive properties are: molecular weight, chain flexibility, hydration (swelling), hydrogen bonding capacity, cross-linking density, charge and concentration.

The ideal molecular weight to obtain the maxim bioadhesion depends on the type of bioadhesive polymer at issue. In fact, the same polymer has got a greater or lower bioadhesive strength depending if it is formulated with a high or low molecular weight, respectively. Theoretically, the threshold required for successful bioadhesion is a molecular weight of about 100,000 KDa. Furthermore, the linear or non-linear polymer structure may influence the mucoadhesion. In particular, interpenetration (for lower molecular weight polymers) and entanglement (for higher molecular weight polymers) are two important features to assess bioadhesiveness of linear molecules [52].

It is well known that the first moment of the bioadhesion is the diffusion of the polymer chains in the interfacial region. Hence, the presence of a certain degree of flexibility of the polymer chains is important to obtain an optimal entanglement with the mucus. Mobility and flexibility of the polymer chains is related to their viscosities and diffusion coefficients; polymers with an higher chain flexibility have a greater diffusion into the mucus network. Furthermore, flexibility may improve the hydrogen bonding potential. Finally, it is important to underline that when water-soluble polymers become cross-linked, mobility of individual polymer chains decrease and thus the effective length of the chain that can penetrate into the mucus layer decreases, thus reducing the bioadhesive performance.

Hydration should be an important feature of mucoadhesive polymers that allow them to expand, to create a bioadhesive network, to induce mobility of their chains in order to enhance the interpenetration process between polymers and mucin molecules. Furthermore, polymer swelling allows mechanical enlargement with the consequent exposure of the bioadhesive sites for hydrogen bonding and/or electrostatic interaction between the polymer and the mucus network.

Swelling depends on the polymer concentration, ionic strength, as well as the presence of water. Overhydration results in the formation of a wet slippery mucilage without adhesion.

Hydrogen bonding capacity is very important for mucoadhesion; polymers with functional groups able to perform hydrogen bonds should be preferred.

Other three important features of the polymer network which must be considered are the average pore number and size, the average molecular weight of the cross-linked polymers and the density of cross-linking. Probably, the degree of hydration and of swelling have an inverse correlation with the cross-linking degree of a polymer. In fact, an increased density of the cross-linking cause a diffusion of water in polymer network at a lower rate, with consequent reduced swelling and insufficient interpenetration of the polymer in the mucus substrate.

The molecular charge of the polymers is also important for mucoadhesion; in particular, the anionic charge of a polymer is an important feature for the mucoadhesive potential. Furthermore, some cationic polymers perform good adhesive properties when they are in neutral or weakly basic medium.

Finally, the polymer concentration is another important factor for mucoadhesion, in particular for the possibility of generating sufficiently long chains to better penetrate the mucus network and 
Table 1. In Vitro and In Vivo Techniques to Study Mucoadhesion. Briefly, the Technique Methods and the Main Advantages and Disadvantages are Discussed

\begin{tabular}{|c|c|c|}
\hline \multicolumn{3}{|c|}{ IN VITRO METHODS } \\
\hline Methods & Characteristics of the method & Advantages and disadvantages \\
\hline $\begin{array}{l}\text { Tensile (de- } \\
\text { tachment) } \\
\text { method }\end{array}$ & $\begin{array}{l}\text { Measurement of the adhesive force between the polymer and biologi- } \\
\text { cal substrate by measuring the force required to break the adhesive } \\
\text { bond by applying an external tensile stress thanks to an automatic } \\
\text { tensile machine. The use of a dual tensiometer which allows to con- } \\
\text { sider also the shear forces in evaluating the adhesive bond strength } \\
\text { has been proposed by some researchers }[65,66] \text {. }\end{array}$ & $\begin{array}{l}\text { The contact force, the testing speed, the contact time and the } \\
\text { environment where the adhesion process occurs (e.g. solution } \\
\text { pH, temperature, concentration of liquid, temperature) influ- } \\
\text { ence the experimental results. } \\
\text { Results obtained from studies using substrate taken from } \\
\text { animal tissues are often characterized by poor reproducibility } \\
\text { due to the variable nature of ex vivo biological substrates. }\end{array}$ \\
\hline $\begin{array}{l}\text { Rotating disc } \\
\text { method }\end{array}$ & $\begin{array}{l}\text { The technique is based on the use of a rotating stainless steel cylinder } \\
\text { covered with samples of biological substrate. The dosage forms (tab- } \\
\text { lets, discs or films) are then applied and compressed on the biological } \\
\text { tissue. The cylinder is then inserted into a dissolution apparatus and } \\
\text { starts rotating at stable and constant speed and temperature. Every } \\
\text { change in the position and state of the dosage form are recorded at } \\
\text { regular intervals until the complete detachment or dissolution of the } \\
\text { dosage form occurs. }\end{array}$ & $\begin{array}{l}\text { The time of complete detachment is considered a marker of } \\
\text { adhesive bond strength and can be used to compare other } \\
\text { different values, obtained under the same experimental condi- } \\
\text { tions, by using other bioadhesives. It has been shown that } \\
\text { data obtained by using this method correlate well with those } \\
\text { obtained by tensile tests for evaluating the adhesive perform- } \\
\text { ance of polymer compounds [68]. }\end{array}$ \\
\hline $\begin{array}{l}\text { Flow-through } \\
\text { method }\end{array}$ & $\begin{array}{l}\text { This technique is often used to evaluate the mucoadhesive properties } \\
\text { of micro-, nano- semi liquid-formulations that can not be easily } \\
\text { evaluated by tensile experiments. It is essential to reproduce in vitro } \\
\text { as closely as possible the in vivo environmental conditions that occur } \\
\text { at the mucosal interface, such as temperature, humidity, volume, } \\
\text { physical features and flow rate of biological fluid. }\end{array}$ & $\begin{array}{l}\text { This method is useful for evaluating the adhesive perform- } \\
\text { ance of dosage forms that must be administered in body re- } \\
\text { gions where mucosal tissues are subjected to the washing } \\
\text { effect of biological fluids, such as the gastrointestinal tract, } \\
\text { the nasal, ocular and vaginal mucosa, and finally the oral } \\
\text { cavity. }\end{array}$ \\
\hline $\begin{array}{l}\text { Rheological } \\
\text { method }\end{array}$ & $\begin{array}{l}\text { The mucoadhesion process is evaluated by simulating the interprene- } \\
\text { tration layer by mixing a polymer solution or dispersion with mucin } \\
\text { solution. The behaviour of mucoadhesive polymer candidates is } \\
\text { determined by comparing the rheological properties of polymer- } \\
\text { mucin mixture with those of the polymer and mucin separately. } \\
\text { Polymers with high adhesive performance exhibit a higher viscosity } \\
\text { in mixtures with mucin when compared to the sum of viscous prop- } \\
\text { erty of the polymer and the mucin considered separately; this } \\
\text { rheological synergism is considered result of the formation of the } \\
\text { adhesive bond between polymer and mucus. It has been shown that } \\
\text { the rheological synergism occurs only within certain polymer concen- } \\
\text { tration ranges and these concentration values depend on the polymer } \\
\text { under study and on the used substrate. }\end{array}$ & $\begin{array}{l}\text { The rheological method is a useful approach to allow easy } \\
\text { and reproducible determination of adhesive properties of a } \\
\text { polymer. The validity of this method has been reinforced by } \\
\text { studies that have shown a good correlation of the order rank } \\
\text { of polymers according to their adhesiveness, by comparing } \\
\text { data obtained using a rheological approach with those ob- } \\
\text { tained by detachment tensile tests. } \\
\text { However, results of rheological tests should be always criti- } \\
\text { cally analysed because, since the isolation of freshly isolated } \\
\text { mucus can be difficult, these tests are often carried out using } \\
\text { commercially dried mucus which is rehydrated before testing. } \\
\text { The authors are quite agreed that the rheological properties } \\
\text { similar to those of freshly isolated mucus can not be obtained } \\
\text { by using rehydrated mucin gels [148]. }\end{array}$ \\
\hline $\begin{array}{l}\text { Fluorescent } \\
\text { probes }\end{array}$ & $\begin{array}{l}\text { Measurement of the change in fluorescence by using fluorescent } \\
\text { probes connected to the mucus substrate when the adhesive polymer } \\
\text { adheres. The degree of change in fluorescence is proportional to the } \\
\text { amount of polymer that binds and thus to the adhesive bond strength. }\end{array}$ & $\begin{array}{l}\text { This technique, based on molecular interactions, allows to } \\
\text { assess if changes in physical-chemical characteristics of the } \\
\text { polymer can influence the adhesion process. }\end{array}$ \\
\hline $\begin{array}{l}\text { Staining tech- } \\
\text { nique }\end{array}$ & $\begin{array}{l}\text { Measurement of the relative staining intensity in samples obtained } \\
\text { after staining with } 0.1 \% \text { Alcian blue or Eosin solution. }\end{array}$ & $\begin{array}{l}\text { The degree of adhesion of the polymer to the biological sub- } \\
\text { strate is measured by using the relative staining intensity, } \\
\text { according to the chemical characteristics of the polymer } \\
{[149] \text {. }}\end{array}$ \\
\hline $\begin{array}{l}\text { Biocore }^{\mathrm{TM}} \text { sys- } \\
\text { tem }\end{array}$ & $\begin{array}{l}\text { Technique to characterize the molecules according to the specificity } \\
\text { of their interactions based on the phenomenon of Surface Plasmon } \\
\text { Reflectance. }\end{array}$ & $\begin{array}{l}\text { This method allows a quantitative real-time measurement of } \\
\text { binding between polymer and mucin. }\end{array}$ \\
\hline $\begin{array}{l}\text { Methods to } \\
\text { Study Mucoad- } \\
\text { hesive Interac- } \\
\text { tions }\end{array}$ & $\begin{array}{l}\text { Infrared, nuclear magnetic resonance and X-ray photoelectron spectrc } \\
\text { interactions }[49,52] .\end{array}$ & opy have been recently proposed to study the mucoadhesive \\
\hline
\end{tabular}


(Table 1) Contd....

\begin{tabular}{|c|c|c|}
\hline \multicolumn{3}{|c|}{ IN VITRO METHODS } \\
\hline $\begin{array}{l}\text { Gamma scinti- } \\
\text { graphy }\end{array}$ & $\begin{array}{l}\text { Technique to track the radiolabelled polymers contained in the dosage form } \\
\text { at the site of application. By means of gamma scintigraphy both the distribu- } \\
\text { tion and retention can be studied. }\end{array}$ & $\begin{array}{l}\text { These techniques are less common due to high cost, } \\
\text { time consuming and ethical factors. But these are } \\
\text { important to assess the true mucoadhesive potential } \\
\text { specially in case of oral mucoadhesive drug delivery. }\end{array}$ \\
\hline $\begin{array}{l}\text { Magnetic reso- } \\
\text { nance imaging } \\
\text { technique }\end{array}$ & $\begin{array}{l}\text { Measurement of the residence time of fluorescent polymers contained in the } \\
\text { dosage form at the site of application [90]. }\end{array}$ & $\begin{array}{l}\text { This technique allows to compare the in vivo muco- } \\
\text { adhesive properties of polymer systems candidates } \\
\text { for oral transmucosal drug delivery [49]. }\end{array}$ \\
\hline
\end{tabular}

to create strong adhesive bonds. Very low polymer concentration is characterized by smaller number of penetrating polymer chains and consequently the interaction between polymer and mucus results unstable. Instead, more concentrate polymers determine longer penetrating chains and a better adhesion. The highest polymer concentrations do not necessarily mean better adhesion; in fact, there is an optimal maximum concentration of a bioadhesive polymer to produce the better mucoadhesion. However, in highly concentrated systems, apart from the optimum concentration level, the adhesive strength is significantly reduced because the coiled molecules become separated from the medium so that the chains available for interpenetration become limited.

\section{ADHESIVE POLYMERS: IDEAL CHARACTERISTICS AND CLASSIFICATION}

After analysing the polymer-related factors influencing the adhesive potential, it is clear what should be the ideal characteristics of a mucoadhesive polymer candidate for insertion in a mucoadhesive dosage form for oral transmucosal delivery, as listed in Table 2.

In general, adhesives polymers can be classified: as synthetic, natural or semi-natural according to source, as water soluble or insoluble according to their solubility, as anionic, cationic or not ionic molecules according to their charge, and depending on the potential adhesive forces that they generate in contact with the mucus substrate as ionic, covalent, hydrogen bonds or electrostatic interactions. Park and Robinson [65] have proposed a classification based on adhesion behavior and distinguish three different broad categories:

1) polymers that become sticky when placed in aqueous medium and their adhesion depends on this stickiness

2) polymers that adhere to the mucous layer by means of noncovalent interactions

3) polymers that bind to specific receptor sites on cell surface.

\subsection{First Generation Mucoadhesive Polymers}

Adhesive polymers defined by Lee as the "first generation" polymers belong to the first two categories. They lack of specificity and targeting ability and bind to the mucus layer by non-specific non-covalent interactions (electrostatic interactions, hydrogen and hydrophobic bonds) and suffer from short retention times due to the rapid rates of mucus turnover.

The first generation polymers include: i) anionic polymers, ii) cationic polymers, iii) non-ionic polymers and iv) amphoteric polymers. Anionic and cationic polymers are those showing the greatest mucoadhesive strength [66].
Thanks to their high mucoadhesive properties and low toxicity the anionic polymers are widely employed in the formulation of several dosage forms. Their negative charge at physiological $\mathrm{pH}$ is due by the carboxyl and sulphate functional groups. The mucoadhesiveness of the polymers belonging to this group is linked to the ability of carboxylic groups to form hydrogen bonds with oligosaccharide chains of mucins.

The most important polymers classified in this group are: poly(acrylic acid) (PAA) and its weakly cross-linked derivatives, sodium carboxymethylcellulose (NaCMC), poly-(methacrylic acid) sodium alginate and poly[(maleic acid)-co-(vinyl methyl ether)].

Examples of polyacrylic acid-based polymers are carbopol $\left(\right.$ Carbopol $\left.^{\circledR}\right)$, carbomers, polycarbophil $\left(\right.$ Noveon $\left.^{\circledR}\right)$, polyacrylate, poly(methylvinylether-co-methacrylic) acid, poly(2-hydroxyethyl methacrylate), poly(methacrylate), poly(alkylcyanoacrylate), poly (isohexylcyanoacrylate), and poly(isobutylcyanoacrylate) [49, 52].

PAA polymers are available in a wide range of molecular weights; they are able to form transparent, easily modified gel networks and are not irritant, not toxic and are considered safe.

Polycarbophil and Carbopol are the more deeply studied PAAbased polymers as mucoadhesive compounds for drug delivery to the gastrointestinal tract, included the oral cavity $[67,68]$. The main features of polycarbophil are its water-insolubility, its high hydration or swelling under neutral $\mathrm{pH}$ conditions, allowing excellent levels of entanglement within the mucus layer. Furthermore, the presence of the non-ionized carboxylic acid groups permits the creation of hydrogen bonds fundamental to bind the mucosal surfaces [66].

In addition to mucoadhesive properties, some anionic polymers such as Carbopols exhibit unique gelation behavior, which can be easily triggered by changes in solution $\mathrm{pH}$. Hence, the possibility to obtain a gel compound (i.e. from a liquid form) and/or to modify the gel behaviour of the polymer in relation to variation of the environmental $\mathrm{pH}$ open excellent opportunities for formulating in situ gelling dosage forms allowing a strong bond with mucosal surface and a consequent improved dosage form retention times.

It is important to underline the existence of a clear distinction between carbomer and polycarbophil especially in terms of crosslinking level and the cross-linking agent itself. Carbomers are cross-linked with allyl-sucrose or allyl-pentaerythritol, whereas polycarbophil polymers are cross-linked with divinyl glycol. These two different cross-linking properties result in a different cross-link density and thus in different pharmaceutical and/or cosmetic applications [49]. 
Table 2. Ten Important Characteristics of an Ideal Mucoadhesive Polymer

\begin{tabular}{|c|l|}
\hline $\mathbf{1 .}$ & To contain a substantial degree of flexibility in order to achieve the desired entanglement with the mucus [150] \\
\hline $\mathbf{2 .}$ & to have a critical molecular weight and an adequate length to allow chain inter-penetration \\
\hline $\mathbf{3 .}$ & $\begin{array}{l}\text { to have anionic or cationic charges. It has been demonstrated that strong anionic or cationic charge on the polymer provide a greater degree of adhe- } \\
\text { sion compared to non-ionic polymers }\end{array}$ \\
\hline $\mathbf{4 .}$ & to have functional groups able to form hydrogen bonds, which are an important factor in mucoadhesion [151] \\
\hline $\mathbf{5 .}$ & to have surface energy properties favouring spreading on a mucus layer [60] \\
\hline $\mathbf{6 .}$ & to not irritate the mucosal surface \\
\hline $\mathbf{7 .}$ & to adhere quickly to moist tissue and not to decompose during retention time of dosage forms \\
\hline $\mathbf{8 .}$ & to not have high cost, so that the prepared dosage form remains feasible \\
\hline $\mathbf{9 .}$ & to allow easy incorporation of the drug and provide drug release in a controlled manner \\
\hline $\mathbf{1 0}$ & to demonstrate local enzyme inhibition and penetration enhancement properties \\
\hline
\end{tabular}

Cationic polymers, as chitosan and polymethacrylates, are also characterized by optimal mucoadhesive properties [69-71]. Chitosan is the most abundant polysaccharide in the world, after cellulose, produced by the alkali $\mathrm{N}$-deacetylation of chitin, the main constituent of crustacean exoskeletons. Chitosan is a polysaccharide with a linear molecular structure of $\beta$-(1-4)-linked 2-amino-2deoxy-D-glucose residues. Its most important physicochemical and biological features include: cationic charge, film forming ability, antimicrobial and wound healing properties, good biocompatibility, favourable toxicological properties, ability to bind lipids and fatty acids and to enhance penetration through mucosal membranes [49, 52]. The high bioadhesive properties of chitosan are related to its close interaction with mucins molecules. Whereas PAAs bind to mucus via hydrogen bonds, chitosan binds via ionic interactions between primary amino functional groups and the sialic acid and sulphonic acid substructures of mucins $[49,52]$.

Although the electrostatic attraction, consisting in the interaction of positively charges of chitosan with negatively charged mucins, is the main mechanism for chitosan mucoadhesion, the hydrogen bonds (among hydroxyl and amino groups) and hydrophobic effects characterize the complex interactions between chitosan and mucins molecules. The linear structure of chitosan molecules also ensures sufficient chain flexibility for the formation of an extensive interpenetration layer. Furthermore, beyond its excellent mucoadhesive performances, it may enhance drug absorption via paracellular route by the neutralization of fixed anionic sites within the tight junctions between mucosal cells [49, 72-74].

Thanks to the presence of active functional groups such as amines and hydroxyls in its structure, it is possible to obtain several derivates (i.e. trimethyl chitosan, glycol chitosan, carboxymethylchitosan and half-acetylated chitosan) from chitosan; however, only in few cases their mucoadhesive properties for transmucosal drug delivery have been reviewed [52, 75-78].

Non-ionic polymers usually show low bioadhesive properties when compared with anionic and cationic molecules. The adhesion with mucins is obtained thanks to the diffusion of the macromolecules and consequent formation of interpenetration layer with mucus gel [52].

Amphoteric polymers or polyampholytes are molecules with both cationic and anionic functional groups in their chains. The most important polyampholytes with mucoadhesive properties are gelatin and N-carboxymethylchitosan. Due to its amphoteric nature and self-neutralization of cationic and anionic charged within its structure, gelatin has low bioadhesive properties as those of the non-ionic polymers. Polyampholytes are characterized by peculiar features which must be taken into account when analysing them to be used for mucoadhesive and penetration-enhancing purposes. In particular, in relation to the $\mathrm{pH}$ solution and to their isoelectric point, amphoteric polymers may exist in three different states: positively charged, neutral and negatively charged, with different structural and physicochemical properties, also affecting mucoadhesive and penetration enhancing properties of polyampholyte-based formulations [52].

\subsection{Second Generation Mucoadhesive Polymers}

By using first generation non-specific polymer, mucoadhesion can occur at any site in addition to that desired for drug release. This consideration is particularly important for dosage forms designed for mucoadhesion in the distal gastrointestinal tract. The second generation of mucoadhesive polymers is characterized by the ability to bind covalently to the mucus layer and adhere directly to the cell surface by means of site-specific receptors and covalent bonds. Furthermore, this characteristic of some polymers, defined as cytoadhesives, makes them less susceptible to mucus turnover rates, ensuring that these polymers provide longer retention times. Furthermore, a site-specific adhesion through specific receptors may trigger intercellular signalling for internalization of drug or carrier system by means endocytosis.

To this group belong: lectins, bacterial adhesion and thiolated polymers or thiomers.

The name lectin derives from the Latin word: legere $=$ to select, that originally described plant extracts capable of agglutinating red blood cells and was found in plants, vertebrates, bacteria, or invertebrates [79]. Today, lectins are naturally occurring glycoproteins of a non-immunoglobulin nature that play a fundamental role in recognition biological phenomena involving cells and proteins. They are capable to recognize specifically and to reversibly bind to carbohydrate residues of glucoconjugates complex present on cell membrane, without altering the covalent structure of any of the recognized glycosyl ligands. As all target-specific polymers, after initial mucosal cell-binding, lectins can either remain on the cell surface or in the case of receptor-mediated adhesion possibly become internalized via a process of endocytosis. Hence, lectins offer three important advantages in drug delivery: they allow the adhesion to a specific target, increase the residence time of the dosage form on the mucosal surface and offer a system for controlled delivery of macromolecular drug via an active cell-mediated drug uptake $[49,80]$. However, lectins present several disadvantages: 
many lectins are toxic or immunogenic and may undergo a premature inactivation by mucus; finally, it is possible that some lectins may stimulate lectin-specific antibody production which may block lectin-mediate adhesion to the epithelial cell surfaces and to induce an anaphylaxis reaction following a subsequent exposure [49, 81]. The use of genetically engineered lectins or lectinomimetics compound with reduced toxicity/immunogenicity has been proposed in order to ensure mucoadhesive proper performances.

The potential adhesive properties of bacterial cells, as a possible adhesion system has been object of study in the recent years [12]. Bacteria are able to adhere to epithelial surfaces by means of bacterial fimbriae. This latter are long, lectin-like proteins found on the surface of many bacterial strains and are strictly linked to bacterial pathogenicity. The phenomenon of the adhesion between fimbriae and mucosal membranes have been investigated and exploited as a means to achieve target-specific drug delivery, to enhance adhesion of particular drug carriers or hydrogels to epithelial surfaces. In particular, K99-fimbriae, an attachment protein derived from $E$. coli, has been covalently attached to PAA networks, showing a better adhesion than controls (unmodified polymers) [82].

Another type of second-generation mucoadhesive polymers are thiolated polymers or thiomers. They can be defined as polymers containing lateral chains with thiol-bearing functional groups. Thiomers are derived from hydrophilic polymers such as polyacrylates, chitosan or deacetylated gellan gum which have been conjugated with molecules carrying thiol functionality (thiolation process). Typical polymers that undergo thiolation are: poly(acrylic acid)/cystein, poly(acrylic acid)-homocysteine, chitosan/N-acetylcystein, alginate/cystein, chitosan/thioglycolic acid, chitosan/thioethylamidine, chitosan-iminothiolane, poly(methacrylic acid)cysteine, sodium carboxymethylcellulose-cysteine [52, 83-89].

The mucoadhesive properties of thiolated polymers are linked to their capability to form covalent bonds (disulfide bridges) with cysteine-rich sub-domains of the glycoproteins of the mucus gel layer through thiol/disulfide exchange reactions or through a simple oxidation of free thiol groups in order to achieved an increased residence time and improved bioavailability [49, 52, 90]. With this behaviour, they mimic the natural mechanism of mucus glycoproteins which are linked to the mucus network through disulphide covalent bonds. Thanks to the formation of these bonds with mucins molecules thiomers have also enhanced mucoadhesive properties in comparison with conventional bioadhesives [91]. Furthermore, the presence of disulphide covalent bonds make thiolated polymers less susceptible to modify their behaviour on the basis of ionic strength and/or $\mathrm{pH}$ changes, when compared with firstgeneration mucoadhesive polymers. However, since these kinds of bonds may increase rigidity and cross-linking degree, the mechanism of drug release from the delivery system based on thiomers could be different [49]. Thiomers have got the capability to bind zinc, resulting in the inhibition of aminopeptidases and carboxypeptidases, which are zinc dependent proteases. This property is highly useful for oral administration of peptide and protein drugs. Finally, the thiolation of non-ionic polymers may increase their bioadhesiveness opening a new scenario for their use [52]. Recently, the potential cytotoxicity of thiolated polymers has been questioned. The possible harmful effects on the cell membrane of thiol derivatives of chitosan were evaluated by assessing cell viability and proliferation rate comparing with the unmodified polymer. In fact, thiolated compounds have shown a lower cell membrane-damaging effect than the unmodified compounds, probably because the thiolation of these polymers determines a greater molecule rigidity due to disulfide bridges, resulting in a reduced attachment to the cell membrane. However, the cytotoxicity of these compounds is a dose-dependent process and occurs at relatively high polymer concentrations that should not compromise the use of these polymers for the formulation of transmucosal dosage forms.

\subsection{Other Mucoadhesive Polymers}

Other polymers that should be mentioned are: polymers with acrylate end groups, dendrimers copolimers, boronic acid copolymers, synthetic glycopolymers, hydrogels and milk protein.

Davidovich-Pinhas and Bianco-Peled have recently proposed $[92,93]$ a new class of mucoadhesive polymers capable of forming covalent bonds with mucins similarly to polymeric thiomers [52]. An example of these polymer is poly(ethylene glycol) diacrylate; however, further studies needed to assess mucoadhesive properties of various polymers with acrylate and methacrylate groups to prove their greater adhesive properties compared to unmodified analogues.

Dendrimers are macromolecules with regular and highly branched three-dimensional structures consisting of a core, branches and end-groups. Their structure and properties make them useful as vectors for gene delivery, excipients for enhancing aqueous solubility of poorly-soluble drugs, antimicrobial agents and drug conjugates $[94,95]$. Until today only few works have been published about the use of dendrimers as mucoadhesives. In particular, it has been reported the use of poly(amidoamine) (PAMAM) dendrimers carrying various functional groups (amino, carboxylate and hydroxyl surface groups) for ocular delivery of pilocarpine nitrate and tropicamide [96].

Copolymers consist in the association of different monomers with varied properties. Recent researches focus their attention on delivery system containing block copolymers rather than a single polymeric system [29]. A block copolymer is obtained when the reaction is carried out in a stepwise manner; the results are chains with long sequences or block or a monomer alternating with long sequences of another one. When these compounds are composed of both hydrophilic and hydrophobic monomers, they are called polymer micelle. These micelles enclose drug molecules, protecting them from the attack of aqueous medium thanks to the presence of hydrophobic monomers. The most common micelle-based systems are formed from poly(ethylene oxide)-b-polypropylene-b-poly (ethylene oxide) tri-block network. Furthermore, there are also graft copolymers, constituted by entire chains of one kind (e.g. polystyrene) with lateral chains of another kind (e.g. polybutadiene), resulting in more resistant compounds [29]. Hence, both kinds of copolymers, block and graft, combine the useful properties of their constituents as behaving as two-phase systems [29].

Boronic acid copolymers have been recently proposed as a novel class of mucoadhesives [97] constituted by water-soluble polymers containing phenyl boronate functional groups to form complexes with carbohydrates [52]. The Authors demonstrated that the copolymers of $\mathrm{N}$-acryloyl-m-aminophenylboronic acidwith $\mathrm{N}$, $\mathrm{N}$-dimethylacrylamide are capable to form insoluble complexes with porcine stomach mucin. Furthermore, they supposed that these mucoadhesive properties could be also used for ocular, nasal and buccal drug delivery. However, none of these routes have been investigated until today.

Glycopolymers are polymers with sugar moieties as pendant groups [98]; they present hybrid properties typical for both polysaccharides and synthetic polymers. The advantages compared to the conventional water-soluble polysaccharides derive from the possibility to manipulate their architecture and physicochemical properties through homo- and copolymerization with monomers of different nature. The use of glycopolymers as mucoadhesive compounds have been studied by Rathi et al. [49, 52, 99] which synthesized a series of novel glycopolymers starting from a free-radical copolymerization of $\mathrm{N}$-(2-hydroxypropyl)methacrylamide with various sugar-containing monomers such as $N$-methacryloylglycylglycylgalactosamine, $\mathrm{N}$-methacryloylglycylglycylfucosylamine, $\mathrm{N}$ methacryloylglycylglycylglucosamine and $N$ methacryloylglycylglycylmannosamine. The presence of copolymers containing fuco- 
sylamine allows selectively adhering to intestinal mucosa with a stronger force compared to fucosylamine-free copolymers.

Hydrogels are defined as "wet adhesives" because they require an adequately wet environment to show their adhesive properties. They are constituted by hydrophilic cross-linked polymers and are able to absorb and to retain a great amount of water $(30 \%-40 \%$, depending on the polymer used) without dissolving themselves. In the oral cavity, the saliva represents the dissolution medium; when drugs are loaded in these hydrogels and they are inserted in the oral cavity, saliva penetrates into the polymer matrix causing a chain relaxation with consequent releasing of the drug molecules through the spaces or channels within the hydrogel network [29].

Several polymers belong to the large family of hydrogels: polyacrylates (carbopol and polycarbophil), ethylene vinyl alcohol, polyethylene oxide, poly vinyl alcohol, poly( $\mathrm{N}$-acryloylpyrrolidine), polyoxyethylenes, self-cross-linked gelatin, sodium alginate, natural gums like guar gum, karaya gum, and cellulose ethers like methyl cellulose, hydroxypropyl cellulose, hydroxy propyl methyl cellulose and sodium carboxy methyl cellulose [29]. Watanabe et al. [100] reported on hydrogels formed by the combination of natural gums, xantham gum, and locust bean gum, as being applicable in buccal delivery systems because of its safety, gel strength sustained release properties and good feel in the mouth [101]. Locust bean gum and xantham gum alone cannot form a hydrogel but when a mixture of these gums is dissolved in a neutral medium at $90^{\circ} \mathrm{C}$ and then cooled with ice for $30 \mathrm{~min}$, a clear, strong hydrogel is formed, showing only a low mucoadhesion.

Finally, milk protein concentrate containing proteins (minimum $85 \%$ ) as Prosobel L85, LR85F at concentration of $15 \%-50 \%$ organized in bioadhesive tablets have showed good bioadhesive properties [29].

\subsection{Multifunctional Polymers}

The formulation of new dosage forms requires the inclusion of a large number of additives to carry out complex tasks in a good way to release a drug such as adequate solubility of the drug, increasing the permeability of drug across the biological membrane the adhesive strength of the dosage form, the inhibition of the enzymatic barrier. Therefore, the search for polymeric compounds that have multiple functions allows easier creation of dosage forms with good features.

Some adhesive polymers, such as PAA and its derivates, have a proved capability of inhibiting the activity of certain proteolytic enzymes. In particular, policarbophil and other carbomers are able to inhibit the activity of trypsin because of their strong affinity to divalent cations $\left(\mathrm{Ca}^{2+}, \mathrm{Zn}^{2+}\right)$, which are universally known as essential cofactors for the proteolytic activity. The depletion of calcium ions, especially at neutral $\mathrm{pH}$, due to the presence of these multifunctional polymers, leads to the formation of the secondary structure of trypsin and the autodegradation of the enzyme itself.

The inhibition of the enzymatic barrier thanks to these polymers is an important factor to consider for the possible transmucosal release of macromolecules such as protein and peptide drugs.

It has been shown also that several adhesive polymers may also affect the permeability of tissues due to the interactions with epithelial cells. The increased permeability, via the paracellular pathway, of several drugs in the presence of some mucoadhesive polymers has been attributed to the ability of these polymers to determine an expansion of the intercellular spaces; in fact, adhesive polymer is usually dry and swellable mucoadhesive and since it accumulates water, causes the dehydration and shrinking of epithelial cells, which ultimately leads to a physical separation of the intercellular junctions. In contrast, other bioadhesive polymers show a different biological effect on epithelial cell permeability barrier, but the exact mechanism of enhancement need to be further clarified. For a detailed description of the mechanisms by which a compound can improve the permeability of a tissue see the review by Veuillez et coworkers [6]

Finally, some polymers such as poloxamer 407, carbopol, hyaluronic acid, and xanthum gum have been reported to act as phase-change polymers. These polymers have the specific characteristics to change their properties in response to external stimuli such as $\mathrm{pH}$, temperature or the presence of ions and other chemical compounds and the induced changes in viscosity of these polymers can be used to ensure a controlled and sustained drug release from dosage forms.

\subsection{Polymers Association and Complexes}

In order to enhance the intrinsic mucoadhesive properties, the mechanical characteristics, to modulate the swelling behaviour and to improve the biocompatibility of different mucoadhesive systems polymers, transmucosal dosage forms can be composed by combining different polymers [102-105]. New mucoadhesive materials are prepared by the association of pharmaceutical polymers in solid state or in solution. Solid state association may be realized through mixing of pulverized excipients and their subsequent compression into mucoadhesive tablets or discs $[30,32,109]$. In this case the final mucoadhesive properties of the dosage form will depend on the strength of specific interactions occurring between components upon hydration. When the interactions between the polymers are not very strong and do not lead to the formation of insoluble polycomplexes, the mucoadhesive properties of a dosage form will be intermediate between the adhesiveness of each individual components.

The association of various polymers in a solution with common solvents is used to prepare liquid and semi-solid mucoadhesive dosage form. Alternatively, solution mixtures may be dried on flat surfaces resulting in mucoadhesive polymeric patches, films or spray-dried microparticulate formulations. The knowledge of specific interactions, which occur between polymers in a common solvent, is important since insoluble complexes are often formed and they may affect the final properties of dosage forms. Further considerations of the effects of specific interactions between polymers within a dosage forms on mucoadhesive performances can be found in a recent review.

\section{FACTORS TO CONSIDER FOR THE FORMULATION DESIGN OF THE MUCOADHESIVE DOSAGE FORMS}

Other than the physiological aspects (structure of the oral mucosa, turnover of the oral epithelium and its permeability, presence/thickness/turnover rate of the mucus layer, presence of saliva and mechanical stresses within the oral cavity) already widely discussed in this manuscript, some pathological, pharmacological and pharmaceutical considerations must be taken into account while designing a mucoadhesive dosage form.

As regards the pathological aspects it is clear that many oral diseases can alter the thickness of the epithelium with consequent alteration of the barrier properties of the oral mucosa, they can influence saliva and mucus secretions affecting the retention of the mucoadhesive system and thus the therapeutic effects [54]. Hence, the knowledge of the possible changes in the oral mucosa and the oral environment under pathological conditions is important for formulating an adequate and effective oral delivery system [12].

From a pharmacological point the design of a transmucosal dosage form must consider: a) where the drug should be delivered: systematically or locally; b) the scheduled dose regimens; c) the target site of action/absorption; d) drug features and e) the site requiring the treatment: teeth, buccal mucosa, periodontal pockets, gums and the entire oral cavity in case of a diffuse disease.

Other pharmacological considerations are linked to the intrinsic features of the drug; its absorption is related to the partition coefficient (the rate between the concentration of a drug in an oil phase 
and dose in an aqueous one; hence, it describes its ability to cross the cellular membranes) that explains as the liphophilic drugs permeate through the transcellular route, whilst the hydrophilic one throughout the paracellular one. However, by modifying chemically the drug, it is possible to make it more or less penetrable via the oral epithelium. For example, if the non-ionized fraction of an ionisable drug is increased, it becomes more penetrable through the paracellular route. In other cases, the modification of the environmental $\mathrm{pH}$ may change drug charge making it more o less absorbable. It is also possible to modify the lipophilicity of a drug by means the acylation or alkylation (a mechanism used to add the Nterminal of the peptidic drug with lipophilic molecules), the conjugation with polymers [as polyethyleneglycol, poly(styrene maleic acid), copolymer, albumin and dextrans] and the methylation.

Pharmaceutical considerations include those factors influencing drug release/kinetics and penetration, organoleptic factors, excipients to avoid enzymatic drug degradation, excipients to enhance permeation and finally, the mucoadhesive polymers deeply analyzed in the manuscript.

Drug release and kinetics from a dosage forms is influenced by polymer matrix morphology (formulated as macro or nanospheres, gel films, extruded shape: cylinder, rod etc.) or by the presence of excipients which modulate polymer and drug degradation. Another factor influencing the development of dosage forms for transmucosal drug delivery via the oral mucosa is the drug free concentration within the dosage form. For being available for transmucosal release, a drug must not only be released from the dosage form but also must be in its free form, i.e. not linked to other components of the dosage form. The lack of drug available in the transmucosal delivery of the device would greatly reduce the bioavailability of the drug.

The presence inclusion of enzyme inhibitors in the formulation is fundamental to avoid the degradation of peptidic drugs. Some protease inhibitors used are: aprotinin, bestatin, puromycin and bile salts. Because more than one enzyme is implicated in drug degradation, it is important to combine more enzymatic inhibitors in the formulation design. Furthermore, to increase the peptidic drug stability it is possible to modify its structure (i.e. substituting some amino-acids in its structure).

A great importance is the addition of chemical permeability enhancers in the formulation of the dosage forms. These excipients facilitate the permeation of the drug through the oral mucosa. An ideal chemical enhancer should be not toxic and not irritating, the absorption-enhancing action should be immediate and unidirectional, the effect of permeation enhancer should be reversible and the enhancer should be physically compatible with a wide range of drugs and pharmaceutical excipients. Finally, it is important to consider that the selection of an enhancer and its efficacy are linked to the physicochemical properties of the drug, site of administration (because there may be differences in epithelial thickness, lipid composition and enzymatic activity the efficacy of an enhancer in one site is not the same than in other).

The most common classes of permeation enhancers are: chelators (EDTA, citric acid, sodium salicylate, methoxy salicylates), surfactants (sodium lauryl sulphate, polyoxyethylene, Polyoxyethylene-9-laurylether, Polyoxythylene-20-cetylether, Benzalkonium chloride, 23-lauryl ether, cetylpyridinium chloride, cetyltrimethyl ammonium bromide), bile salts (sodium glycocholate, sodium deoxycholate, sodium taurocholate, sodium glycodeoxycholate, sodium taurodeoxycholate), fatty acids (oleic acid, capric acid, lauric acid, lauric acid/propylene glycol, methyloleate, lysophosphatidylcholine, phosphatidylcholine), non-surfactants (unsaturated cyclic ureas), inclusion complexes (cyclodextrins), thiolated polymers: chitosan-4-thiobutylamide, chitosan-4-thiobutylamide/GSH, chitosan-cysteine, Poly(acrylic acid)-homocysteine, polycarbophilcysteine, polycarbophil-cysteine/GSH, chitosan-4-thioethylamide/
GSH, chitosan-4-thioglycholic acid, novel chitosan derivates: methyl-pyrrolidone chitosan and the more recent 5-methylpyrrolidone) and others: aprotinin, azone, cyclodextrin, dextran sulfate, menthol, polysorbate, sulfoxides, terpenes, cod-liver oil extracts, lysalbinic acids and various alkyl glycosides.

Chemical permeation enhancers improve drug mucosal absorption through several mechanisms of action: changing mucus rheology (changing mucus viscosity), increasing the fluidity of epithelial cell membrane (disturbing intra-cellular lipid packing by interaction with either lipid packing or protein components and finally increasing the fluidity of lipid bilayer membrane), acting on the component of tight junctions as desmosomes, by overcoming the enzymatic barrier (inhibiting peptidases and proteases) and finally, increasing the thermodynamic activity of drug (altering the partition coefficient of a drug).

\section{MUCOADHESIVE DOSAGE FORM FOR ORAL TRANS- MUCOSAL DRUG DELIVERY}

Since oral cavity offers many advantages for local or systemic drug delivery within/throughout the oral mucosa, the development of mucoadhesive dosage forms has been widely exploited in order to provide a targeted and controlled drug release profile. Whilst first generation bioadhesives have been extensively investigates, especially for the topic treatment of oral diseases, more recent investigations have focused on the systemic controlled delivery of drugs, especially peptides, proteins and polysaccharides.

According to the mechanism by which drug is released from delivery device, dosage forms can be classified in the following categories: monolithic (or "matrix") and reservoir type. In the monolithic type systems, the drug is uniformly dispersed or dissolved in the polymer matrix and drug release is provided by diffusion trough the polymer network. In the reservoir (or membrane controlled) systems, a drug reservoir is entrapped between an impermeable backing layer and a polymeric membrane which controls the drug release rate. The favourite dosage forms are usually the membrane-controlled systems because they promote an unidirectional drug release in the site of action and minimize drug leakage in the oral cavity. Furthermore, other desirable attributes of a mucoadhesive system for oral transmucosal drug delivery are a high drug loading capacity, not irritancy, good mucoadhesion and residence times, smallness and flexibility enough to be acceptable by users, tastelessness and sustained drug release [42].

Erodible formulations can be useful because they do not require system retrieval at the end of application.

Mucoadhesive systems include solid dosage forms as adhesive tablets, patches and films, semi-solid and liquid dosage forms and they will be discussed briefly. These dosage forms have been developed to treat both local and systemic conditions.

\subsection{Adhesive Tablets}

Several bioadhesive tablet systems have been the subject of a growing interest [103, 106-109] in order to improve bioavailability of drug administered across buccal mucosa. Adhesive tablets are small, flat and oval with a diameter approximately of 5-8 $\mathrm{mm}$ and about $2 \mathrm{~mm}$ in thickness [44]. In presence of saliva, they adhere to the mucosal surface until dissolution and/or drug release is complete. After a short time of presence of tablet in the mouth, patient is not jet aware of its presence, allowing to speak, drink and eat without discomfort. Adhesive tablets can be applied to different sites in the oral cavity, including the palate, the mucosa of the cheeks or in any comfortable position between lip and gum in the case of patient wearing dentures. Since the amount of drug delivered is directly proportional to the surface area, the tablet size and shape are also important factors to be considered. A common approach to avoid clearance of the tablet dosage form from the site of application is to place it under the upper lip, as recommended for the application of Buccasteam ${ }^{\circledR}$, an adhesive tablet containing the 
antiemetic prochlorperazine maleate. Recently, mucoadhesive tablets, containing chlorexhidine, were designed to swell and form a gel adhering to the mucosa and controlling the drug release into the oral cavity [110]. These tablets were developed by direct compression, containing different amounts of hydroxypropylmethylcellulose (HPMC) and carbomer; changing the amount ratio of these excipients in formulations, it is possible easily modulate the mucoadhesive effect and release of drug.

In order to prevent drug loss from the top surface of the dosage form, specialized tablets with two layers have been developed. They contain a drug-loaded bioadhesive layer and an impermeable backing layer to promote unidirectional drug absorption and to minimize drug leakage in the oral cavity. In order to achieve unidirectional release with minimal drug loss, drug can released only from the face of the tablet in contact with the buccal mucosa and other faces are coated with water impermeable hydrophobic substances (e.g. ethylcellulose, oil). Bi-layered adhesive tablets containing nystatin were designed with a potential use in the treatment of oral candidiasis [111]. In a recent study, these tablets were applied on 5 healthy volunteers' gum to obtain residence times and subjective parameters. Patient comfort and mucoadhesive behaviour were found to be satisfactory [112]. In addition, in a large randomised trial, miconazole tablets applied once daily was shown to be efficient and reduced the need for the repeated applications in the treatment of oral candidiasis in HIV-positive patients [113]. Furthermore, new mucoadhesive prolonged release tablet containing clobetasol was found to be more effective than clobetasol ointment for the management of oral lichen planus [114].

Several investigators $[115,116]$ have reported the development of mucoadhesive drug delivery devices containing a fast-release and a controlled-release layer. The fast release layer contains poly(vinyl pyrrolidone) (PVP) as the bioadhesive component and is designed to adhere to the buccal mucosa and the controlled release layer consist of a mixture of PVP and poly(acrylic acid) and is intended to adhere to the gingival mucosa.

Different drugs for chronic therapies have been loaded in adhesive tablets, such as propanolol, timolol, metronidazole, carbamazepine metoclopramide, morphine sulphate, nitroglycerin and codein [117-119]. Peptides, such as insulin, melatonin [120], calcitonin and glucagone-like peptide were also loaded in buccal mucoadhesive tablets [6, 121-123]. The main disadvantage of this buccal dosage form is the lack of physical flexibility, leading to high patient discomfort and poor patient compliance due to the material applied to the mucosa, especially for long term therapy and repeated use. Furthermore, the tablets should not be moved once in position because its separation from mucosal surface causes more rapid drug release and the possibility of swallowing the device and subsequently its adhesion to the mucosal surface of the oesophagus.

\subsection{Adhesive Patches}

Laminated patches are a new type of buccal delivery systems, promising not only for systemic drug delivery [124, 125]. The first step in the development of an adhesive patch is the selection and characterization of a polymer with appropriate bioadhesive properties and drug release control or combined polymers in order to obtain both of these properties [126, 127]. Bioadhesive patches are laminates consisting of a polymeric drug-loaded layer, an impermeable backing layer to promote unidirectional drug release and, generally, mucoadhesive components with or without release retardants and additives, such as penetration enhancers or enzyme inhibitors [128]. Anders et al [129] have investigated a number of polymers and different geometries for developing patches for the delivery of different peptides. Veillard et al. [130] designed a unidirectional buccal patch consisting of three different layers: an impermeable backing layer, a rate limiting central membrane containing the drug, and a mucoadhesive layer containing bioadhesive polymer polycarbophil. This patch was tested in dog buccal mucosa and was shown to remain in place for up to 17 hours without any obvious discomfort. A similar three-layer patch was designed and tested on humans, resulting in a in situ placement for up to $15 \mathrm{~h}$ regardless of eating or drinking [131].

Mucoadhesive patches containing local anaesthetics (DentiPatch $^{\mathrm{TM}}$ ) have been formulated for site-specific drug delivery that purportedly maximizes the effect of anaesthetics diffusing into a localized mucosal site to reducing pain associated with injections [132]. Recently, an in vitro study demonstrated for the first time as a bioadhesive patches for dose controlled delivery of imiquimod, an immunomodulator may be potentially used for the treatment of dysplastic/neoplastic conditions of the oral cavity and cervix, as well as the vulva [133]. Different drugs have been loaded in buccal patches for local administration, such as diclofenac, tannic and boric acids [117]. Moreover, buccal patches for systemic delivery of tyrotropin-releasing hormone, octreotide, oxytocin, buserelin, calcitonin and leuenkephalin have been studied for chronic therapies $[6,126,134]$.

Despite of long manufacturing times and costs, oral patches has high flexibility, thus resulting in a long residence time and high patient compliance and comfort. Furthermore, they perform a more accurate dosing of drug delivery respect other dosage forms, such as gels and sprays; finally, patches, thanks to their flexibility and good retention time, protect the underlying diseased tissues, thus reducing pain and increasing the treatment effectiveness.

\subsection{Adhesive Films or Pellicles}

Films are the most recently developed dosage form for buccal administration. Bioadhesive films are similar to laminated patches in term of manufacturing process, advantages and drawbacks. Bioadhesive films should be flexible, elastic, and soft, yet adequately strong to withstand breakage due to stress from mouth movements. It must also possess good bioadhesive strength in order to be retained in the mouth for the desired duration of action. Swelling of film, if it occurs, should not be too extensive in order to prevent discomfort. Multi-layer films, comprising two or more layers connected with each other, was recently developed. These dosage forms, having a thickness of less than $1 \mathrm{~mm}$, do not cause a foreign body sensation, thus contributing to increase patient compliance and comfort. The mucoadhesive layer, containing drug molecules, is capable of swelling in an aqueous medium, although it is insoluble or only poor soluble in such media. Thanks to the mixture of two or more polymers, a fast release and slow release layers can be obtained. The mucoadhesive layer is connected with a backing layer that is mono- or double-layers and which may serve as an active substance reservoir [135].

Some of these dosage forms are not completely water soluble and could remain in the oral cavity even after therapeutic goal has been achieved. In order to reduce patient discomfort due to the not erodible support layer which leaves an insoluble residue in the mouth, an erodible film composition, containing water-soluble polymers, has been introduced [136]. These dosage forms, in which instant wettability causes the film to soften immediately after application to the mucosal tissue, are characterized by rapid dissolution/disintegration after the achieved therapeutic effects, thus preventing the patient from experiencing any prolonged adverse feeling in the mouth. Oral adhesive amlexanox pellicles provide a better flexibility, leading to a higher compliance and patient comfort, in comparison with adhesive tablets during the treatment of recurrent oral ulcerations [137]. Moreover, adhesive films have also the advantage of providing better residence times than oral gels on the mucosa, which are easily washed away and removed by saliva. Finally, a polymeric adhesive film is able to protect the wound surfaces, thus reducing pain and treating the oral disease more effectively [138]. The use of buccal films for buccal drug delivery of vaccines has been also reported. The buccal mucosa may be a very 
interesting site for mucosal immunization, allowing for needle-free administration of cost-effective vaccines [42].

\subsection{Adhesive Semi-solid Systems (Gels, Ointments)}

Semi-solid dosage forms, such as gels and ointments, have the advantage of easy dispersion throughout the oral mucosa. They form an intimate contact with the mucosal membrane and rapidly release drug at the absorption site [139]. However, drug dosing from semisolid dosage forms may not be as accurate as from tablets, patches, or films. Poor retention time of the gels at the site of application has been overcome by using bioadhesive formulations. Nevertheless, despite of bioadhesive polymers, residence time of gels is small since body fluids such as saliva will quickly wash they away from the site of action. For these reasons, they are of limited use for drugs with a narrow therapeutic window. Bioadhesive gels for application on oral mucosa in the treatment of some oral disease have been known for many years. A major application of adhesive gels is the local delivery of medicinal agents for the treatment of periodontitis, recurrent aphthous stomatitis, radio/chemotherapyinduced oral mucositis, oral lichen planus, hyposalivation and recently for wound healing. Orabase ${ }^{\circledR}$, a first generation mucoadhesive paste, has been used as barrier protecting the underlying tissues in presence of mucosal ulcers. It has been suggested that mucoadhesive polymer-based semi-solid dosage forms might be useful for periodontitis therapy when incorporated in antimicrobial-containing formulations as doxycycline, minocyclyne or metronidazole gels, because of their flow property, easy placement with a syringe and retention within the periodontal pocket [124], in order to provide a controlled local drug release $[140,141]$. A low-dose doxycycline in a mucoadhesive gel has been demonstrated to reduce pain in the treatment of recurrent oral ulcerations [142]. Furthermore, hyaluronic acid has been demonstrated to be an essential compound during tissue regeneration and wound healing [143]. Bioadhesive ointments and lipid microspheres have not been described in the literature as extensively as other dosage forms, especially when compared to tablets and patches [12, 144].

\subsection{Adhesive Liquid Systems (Sprays, Oral Rinse)}

Adhesive liquid systems produce a very fine mist, which tends to coat the entire oral mucosa, thereby increasing the total surface area through which drug molecules can be absorbed. Compositions having high mucoadhesion and viscoelasticity, were suggested for the treatment of oral mucosal disease thanks to their film-forming properties. An ideal adhesive spray system could be able to produce sprays patterns of a suitable ovality and particle size, a suitable behaviour and to be delivered in an appropriate unit dose volume to avoid unintended administration through the gastrointestinal tract by swallowing [59].

Bioadhesive liquid systems (oral rinse and sprays) have been proposed for the treatment of several oral diseases, such as oral lichen planus and other immunologically mediated diseases, aphthous ulcerations, oral mucositis, hyposalivation and finally potentially malignant disorders [145]. Recently, a spray compound containing a pool of collagen precursor aminoacids combined with low molecular weight sodium hyaluronate has been shown to be very effective in the treatment of radio/chemotherapy-induced oral mucositis [146]. The advantages of a such kind of liquid delivery systems compared with a gel formulation in the treatment of atrophic erosive disease associated with severe pain is to allow a better distribution in the oral cavity. Oral insulin spray has been proposed as alternative to the insulin injections. When compared with subcutaneous insulin injection, this insulin spray, called Oralin ${ }^{\circledR}$, clearly showed a faster rapid absorption and a comparable metabolic control in both type 1 and type 2 diabetic patients [147].

\section{CONCLUSION}

The safety and efficacy of current treatment regimens could find some advantages from the use of transdermal or transmucosal administration routes. In particular, the oral mucosa offers a promising site in terms of easy accessibility, dosage form retentivity, low enzyme activity, good drug bioavailability and high patient compliance. The use of adhesive polymers in the formulation of mucoadhesive dosage forms, alternatives to the conventional ones, has been proposed to improve the contact time between dosage forms and mucosal surface, showing a significant improvement in drug bioavailability; thus a site-specific targeting can be predicted, monitored, controlled and sustained, ensuring effective systemic treatment regimens and better patient compliance. In addition, mucoadhesive dosage forms have been designated also to treat local disorders, to reduce the required doses and minimize side effects that may be caused by systemic administration of drugs.

The development of transmucosal dosage forms requires the knowledge and the evaluation of several parameters such as parameters related to physiological and pathological features of the oral mucosa and environment and parameters related to the intrinsic characteristics of the polymers. Researchers are focusing on new polymer generation which bond strength is less related to the conditions of the mucus substrate, ensuring high adhesive performances in any condition, and on the combining multiple functions in a single mucoadhesive compound. The physic-chemical characteristics of the drug to be administered and its possible ability to bind the dosage form excipients and to pass through spaces within the polymer network must also be considered.

In this complex scenario, virtually ideal mucoadhesive dosage forms can only be achieved by combining two or more polymers with special properties, and manipulating the formulation of strategies such as the inclusion of $\mathrm{pH}$ modifiers, enzyme inhibitors, permeation enhancers, etc..

To date, oral transmucosal solid, semi-solid and liquid dosage forms have been developed for both systemic and topical drug administration. The future direction of these delivery systems is the possibility to formulate vaccines and to deliver macromolecular drugs, such as proteins and peptides, which can not be effectively administered by means of the most conventional routes.

\section{CONFLICT OF INTEREST}

The authors confirm that this article content has no conflicts of interest.

\section{ACKNOWLEDGEMENTS}

The first two authors contributed in equal measure to the paper.

\section{REFERENCES}

[1] Sayani AP, Chien YW. Systemic delivery of peptides and proteins across absorptive mucosae. Crit Rev Ther Drug Carrier Syst 1996; 13: 85-184.

[2] Song Y, Wang Y, Thakur R, Meidan VM, Michniak B. Mucosal drug delivery: membranes, methodologies, and applications. Crit Rev Ther Drug Carrier Syst 2004; 21: 195-256.

[3] Lee VH. Mucosal drug delivery. J Natl Cancer Inst Monogr 2001: 41-4.

[4] Harris D, Robinson JR. Drug delivery via the mucous membranes of the oral cavity. J Pharm Sci 1992; 81: 1-10.

[5] Hao J, Heng PW. Buccal delivery systems. Drug Dev Ind Pharm 2003; 29: 821-32.

[6] Veuillez F, Kalia YN, Jacques Y, Deshusses J, Buri P. Factors and strategies for improving buccal absorption of peptides. Eur J Pharm Biopharm 2001; 51: 93-109.

[7] Birudaraj R, Mahalingam R, Li X, Jasti BR. Advances in buccal drug delivery. Crit Rev Ther Drug Carrier Syst 2005; 22: 295-330.

[8] Khutoryanskiy VV. Advances in mucoadhesion and mucoadhesive polymers. Macromol Biosci 2011; 11: 748-64.

[9] Smart JD. Buccal drug delivery. Expert Opin Drug Deliv 2005; 2 : 507-17.

[10] Harris D, Robinson JR. Bioadhesive polymers in peptide drug delivery. Biomaterials 1990; 11: 652-8. 
[11] Senel S, Hincal AA. Drug permeation enhancement via buccal route: possibilities and limitations. J Control Release 2001; 72: 133-44.

[12] Salamat-Miller N, Chittchang M, Johnston TP. The use of mucoadhesive polymers in buccal drug delivery. Adv Drug Deliv Rev 2005; 57: 1666-91.

[13] Chen SY, Squier CA. The ultrastructure of the oral epithelium. In Meyer J, Squier CA, Gerson SJ, Eds. The structure and function of oral mucosa. Pergamon Press: London 1984, pp. 7-30.

[14] Gandhi RB, Robinson JR. Oral cavity as a site for bioadhesive drug delivery. Adv. Drug Deliv. rev. 1994; 13: 43-74.

[15] Shojaei AH. Buccal mucosa as a route for systemic drug delivery: a review. J Pharm Pharm Sci 1998; 1: 15-30.

[16] Squier CA, Johnson NW, Hopps RM, Eds. Human oral mucosa: development, structure and function. Oxford (UK): Blackwell Scientific 1976.

[17] Collins LM, Dawes C. The surface area of the adult human mouth and thickness of the salivary film covering the teeth and oral mucosa. J Dent Res 1987; 66: 1300-2.

[18] Rathbone MJ, Hadgraft J. Absorption of drugs from the human oral cavity. Int J Pharm 1991; 74: 9-24.

[19] Squier CA, Johnson NW. Permeability of oral mucosa. Br Med Bull 1975; 31: 169-75.

[20] Campisi G, Paderni C, Saccone R, Di Fede O, Wolff A, Giannola LI. Human buccal mucosa as an innovative site of drug delivery. Curr Pharm Des 2010; 16: 641-52.

[21] Squier CA. The permeability of keratinized and nonkeratinized oral epithelium to horseradish peroxidase. J Ultrastruct Res 1973; 43: 160-77.

[22] Squier CA, Wertz PW. Structure and function of the oral mucosa and implications for drug delivery. In Rathbone MJ, Ed. Oral Mucosal Drug Delivery. New York: Marcel Dekker 1996.

[23] Wertz PW, Squier CA. Cellular and molecular basis of barrier function in oral epithelium. Crit Rev Ther Drug Carrier Syst 1991; 8: 237-69.

[24] Wertz PW, Swartzendruber DC, Squier CA. Regional variation in the structure and permeability of oral mucosa and skin. Adv. Drug Deliv Rev 1993; 12: 1-12.

[25] Squier CA, Kremer MJ. Biology of oral mucosa and esophagus. J Natl Cancer Inst Monogr 2001; (29): 7-15.

[26] Galey WR, Lonsdale HK, Nacht S. The in vitro permeability of skin and buccal mucosa to selected drugs and tritiated water. J Invest Dermatol 1976; 67: 713-7.

[27] Squier CA, Cox P, Wertz PW. Lipid content and water permeability of skin and oral mucosa. J Invest Dermatol 1991; 96: 123-6.

[28] Squier CA, Wertz PW, Cox P. Thin-layer chromatographic analyses of lipids in different layers of porcine epidermis and oral epithelium. Arch Oral Biol 1991; 36: 647-53.

[29] Sudhakar Y, Kuotsu K, Bandyopadhyay AK. Buccal bioadhesive drug delivery--a promising option for orally less efficient drugs. J Control Release 2006; 114: 15-40.

[30] Zhang H, Zhang J, Streisand JB. Oral mucosal drug delivery: clinical pharmacokinetics and therapeutic applications. Clin Pharmacokinet 2002; 41: 661-80.

[31] Madison KC, Sando GN, Howard EJ, et al. Lamellar granule biogenesis: a role for ceramide glucosyltransferase, lysosomal enzyme transport, and the Golgi. J Investig Dermatol Symp Proc 1998; 3: 80-6.

[32] Madison KC, Swartzendruber DC, Wertz PW, Downing DT. Presence of intact intercellular lipid lamellae in the upper layers of the stratum corneum. J Invest Dermatol 1987; 88: 714-8.

[33] Matoltsy AG. Keratinization. J Invest Dermatol 1976; 67: 20-5.

[34] Squier CA. Zinc iodide-osmium staining of membrane-coating granules in keratinized and non-keratinized mammalian oral epithelium. Arch Oral Biol 1982; 27: 377-82.

[35] Lavker RM. Membrane coating granules: the fate of the discharged lamellae. J Ultrastruct Res 1976; 55: 79-86.

[36] Squier CA. Membrane coating granules in nonkeratinizing oral epithelium. J Ultrastruct Res 1977; 60: 212-20.

[37] Wearley LL. Recent progress in protein and peptide delivery by noninvasive routes. Crit Rev Ther Drug Carrier Syst 1991; 8: 33194

[38] Stratford RE, Jr., Lee VH. Aminopeptidase activity in albino rabbit extraocular tissues relative to the small intestine. J Pharm Sci 1985; $74 \cdot 731-4$
[39] Kashi SD, Lee VH. Enkephalin hydrolysis in homogenates of various absorptive mucosae of the albino rabbit: similarities in rates and involvement of aminopeptidases. Life Sci 1986; 38: 2019-28.

[40] Thomson PJ, Potten CS, Appleton DR. Mapping dynamic epithelial cell proliferative activity within the oral cavity of man: a new insight into carcinogenesis? Br J Oral Maxillofac Surg 1999; 37: 377 83 .

[41] Zimmer R, Ashburn MA. Noninvasive drug delivery. Compr Ther 2001; 27: 293-301.

[42] Bruschi ML, de Freitas O. Oral bioadhesive drug delivery systems. Drug Dev Ind Pharm 2005; 31: 293-310.

[43] Mandel ID. Biochemical aspects of calculus formation. II. Comparative studies of saliva in heavy and light calculus formers. J Periodontal Res 1974; 9: 211-21.

[44] Rathbone MJ, Drummond B, Tucker I. Oral cavity as a site for systemic drug delivery. Adv. Drug Deliv. rev. 1994; 13: 1-22.

[45] Levine MJ, Reddy MS, Tabak LA, et al. Structural aspects of salivary glycoproteins. J Dent Res 1987; 66: 436-41.

[46] Marriot C. Gregory N, Eds. Bioadhesive Drug Delivery Systems. Boca Raton: CRC Press 1990

[47] Peppas NA, Sahlin JJ. Hydrogels as mucoadhesive and bioadhesive materials: a review. Biomaterials 1996; 17: 1553-61.

[48] Tabak LA, Levine MJ, Mandel ID, Ellison SA. Role of salivary mucins in the protection of the oral cavity. J Oral Pathol 1982; 11 : $1-17$

[49] Andrews GP, Laverty TP, Jones DS. Mucoadhesive polymeric platforms for controlled drug delivery. Eur J Pharm Biopharm 2009; 71: 505-18.

[50] Harding SE, Creeth JM. Polyelectrolyte behaviour in mucus glycoproteins. Biochim Biophys Acta 1983; 746: 114-9.

[51] Harding SE, Rowe AJ, Creeth JM. Further evidence for a flexible and highly expanded spheroidal model for mucus glycoproteins in solution. Biochem J 1983; 209: 893-6.

[52] Khutoryanskiy VV. Advances in mucoadhesion and mucoadhesive polymers. Macromol Biosci 2011; 11: 748-64.

[53] Gandhi RB, Robinson JR. Bioadhesion in drug delivery. Ind J Pharm Sci 1988; 81: 145-52.

[54] Khanvilkar K, Donovan MD, Flanagan DR. Drug transfer through mucus. Adv Drug Deliv Rev 2001; 48: 173-93.

[55] Sankar V, Hearnden V, Hull K, et al. Local drug delivery for oral mucosal diseases: challenges and opportunities. Oral Dis 2011; 17 Suppl 1: 73-84

[56] Hearnden V, Sankar V, Hull K, et al. New developments and opportunities in oral mucosal drug delivery for local and systemic disease. Adv Drug Deliv Rev 2012; 64(1): 16-28.

[57] Scholz OA, Wolff A, Schumacher A, et al. Drug delivery from the oral cavity: focus on a novel mechatronic delivery device. Drug Discov Today 2008; 13: 247-53.

[58] Mirth DB. Controlled-release therapeutic systems: technology applicable to the treatment of oral disease. Adv Dent Res 1987; 1 : 109-18

[59] Hiremath PS, Bhonsle SA, Thumma S, Vemulapalli V. Recent patents on oral combination drug delivery and formulations. Recent Pat Drug Deliv Formul 2011; 5: 52-60.

[60] Lee JW, Park JH, Robinson JR. Bioadhesive-based dosage forms: the next generation. J Pharm Sci 2000; 89: 850-66.

[61] Chickering III D.E., Mathiowitz E., Bioadhesive drug delivery systems. Fundamentals, novel approaches, and developments. In Mathiowitz E, Chickering III DE, Lehr CM. Eds., Definitions mechanisms and theories of bioadhesion. New York: Marcel Dekker 1999, pp. 1-10.

[62] Kinloch A. The science of adhesion, J Mater Sci 1980; 15: 2141 66.

[63] Dodou D, Breedveld P, Wieringa PA. Mucoadhesives in the gastrointestinal tract: revisiting the literature for novel applications. Eur J Pharm Biopharm 2005; 60: 1-16.

[64] Ugwoke MI, Agu RU, Verbeke N, Kinget R. Nasal mucoadhesive drug delivery: background, applications, trends and future perspectives. Adv Drug Deliv Rev 2005; 57: 1640-65.

[65] Park K, Robinson J. Bioadhesive polymers as platforms for oralcontrolled drug delivery: method to study bioadhesion. Int. J Pharm1984; 19: 107-27.

[66] Ludwig A. The use of mucoadhesive polymers in ocular drug de livery. Adv Drug Deliv Rev 2005; 57: 1595-639. 
[67] Singla AK, Chawla M, Singh A. Potential applications of carbomer in oral mucoadhesive controlled drug delivery system: a review. Drug Dev Ind Pharm 2000; 26: 913-24.

[68] Khutoryanskiy VV. Hydrogen-bonded interpolymer complexes as materials for pharmaceutical applications. Int J Pharm 2007; 334: 15-26.

[69] Fefelova NA, Nurkeeva ZS, Mun GA, Khutoryanskiy VV. Mucoadhesive interactions of amphiphilic cationic copolymers based on [2-(methacryloyloxy)ethyl]trimethylammonium chloride. Int $\mathrm{J}$ Pharm 2007; 339: 25-32.

[70] Sogias IA, Williams AC, Khutoryanskiy VV. Why is chitosan mucoadhesive? Biomacromolecules 2008; 9: 1837-42.

[71] Keely S, Rullay A, Wilson C, et al. In vitro and ex vivo intestinal tissue models to measure mucoadhesion of poly (methacrylate) and N-trimethylated chitosan polymers. Pharm Res 2005; 22: 38-49.

[72] Soane RJ, Frier M, Perkins AC, Jones NS, Davis SS, Illum L. Evaluation of the clearance characteristics of bioadhesive systems in humans. Int J Pharm 1999; 178: 55-65.

[73] Bravo-Osuna I, Ferrero C, Jimenez-Castellanos MR. Influence of moisture content on the mechanical properties of methyl methacrylate-starch copolymers. Eur J Pharm Biopharm 2007; 66: 63-72.

[74] Bravo-Osuna I, Vauthier C, Farabollini A, Palmieri GF, Ponchel G. Mucoadhesion mechanism of chitosan and thiolated chitosanpoly(isobutyl cyanoacrylate) core-shell nanoparticles. Biomaterials 2007; 28: 2233-43.

[75] Qu X, Khutoryanskiy VV, Stewart A, et al. Carbohydrate-based micelle clusters which enhance hydrophobic drug bioavailability by up to 1 order of magnitude. Biomacromolecules 2006; 7: 3452-9.

[76] Qu XH, Wu Q, Zhang KY, Chen GQ. In vivo studies of poly(3hydroxybutyrate-co-3-hydroxyhexanoate) based polymers: biodegradation and tissue reactions. Biomaterials 2006; 27: 3540-8.

[77] Sajomsang W, Tantayanon S, Tangpasuthadol V, Daly WH. Quaternization of $\mathrm{N}$-aryl chitosan derivatives: synthesis, characterization, and antibacterial activity. Carbohydr Res 2009; 344: 2502-11.

[78] Rekha MR, Sharma CP. Synthesis and evaluation of lauryl succinyl chitosan particles towards oral insulin delivery and absorption. J Control Release 2009; 135: 144-51.

[79] Lis H, Sharon N. Lectins as molecules and as tools. Annu Rev Biochem 1986; 55: 35-67.

[80] Lehr CM. Lectin-mediated drug delivery: the second generation of bioadhesives. J Control Release 2000; 65: 19-29.

[81] Clark MA, Hirst BH, Jepson MA. Lectin-mediated mucosal delivery of drugs and microparticles. Adv Drug Deliv Rev 2000; 43: 207-23.

[82] Bernkop-Schnurch A. Mucoadhesive polymers: strategies, achievements and future challenges. Adv Drug Deliv Rev 2005; 57 : 1553-5.

[83] Guggi D, Marschutz MK, Bernkop-Schnurch A. Matrix tablets based on thiolated poly(acrylic acid): $\mathrm{pH}$-dependent variation in disintegration and mucoadhesion. Int J Pharm 2004; 274: 97-105.

[84] Schmitz T, Grabovac V, Palmberger TF, Hoffer MH, BernkopSchnurch A. Synthesis and characterization of a chitosan-N-acetyl cysteine conjugate. Int J Pharm 2008; 347: 79-85.

[85] Schmitz T, Hombach J, Bernkop-Schnurch A. Chitosan-N-acetyl cysteine conjugates: in vitro evaluation of permeation enhancing and P-glycoprotein inhibiting properties. Drug Deliv 2008; 15: 245-52.

[86] Bernkop-Schnurch A, Clausen AE, Hnatyszyn M. Thiolated polymers: synthesis and in vitro evaluation of polymer-cysteamine conjugates. Int J Pharm 2001; 226: 185-94.

[87] Bernkop-Schnurch A, Zarti H, Walker GF. Thiolation of polycarbophil enhances its inhibition of intestinal brush border membrane bound aminopeptidase N. J Pharm Sci 2001; 90: 1907-14.

[88] Sakloetsakun D, Hombach JM, Bernkop-Schnurch A. In situ gelling properties of chitosan-thioglycolic acid conjugate in the presence of oxidizing agents. Biomaterials 2009; 30: 6151-7.

[89] Kafedjiiski K, Hoffer M, Werle M, Bernkop-Schnurch A. Improved synthesis and in vitro characterization of chitosanthioethylamidine conjugate. Biomaterials 2006; 27: 127-35.

[90] Albrecht K, Greindl M, Kremser C, Wolf C, Debbage P, BernkopSchnurch A. Comparative in vivo mucoadhesion studies of thiomer formulations using magnetic resonance imaging and fluorescence detection. J Control Release 2006; 115: 78-84.

[91] Grabovac V, Guggi D, Bernkop-Schnurch A. Comparison of the mucoadhesive properties of various polymers. Adv Drug Deliv Rev 2005; 57: 1713-23.
[92] Davidovich-Pinhas M, Bianco-Peled H. Alginate-PEGAc: a new mucoadhesive polymer. Acta Biomater 2011; 7: 625-33.

[93] Davidovich-Pinhas M, Bianco-Peled H. Novel mucoadhesive system based on sulfhydryl-acrylate interactions. J Mater Sci Mater Med 2010; 21: 2027-34.

[94] Chen CZ, Beck-Tan NC, Dhurjati P, van Dyk TK, LaRossa RA, Cooper SL. Quaternary ammonium functionalized poly(propylene imine) dendrimers as effective antimicrobials: structure-activity studies. Biomacromolecules 2000; 1: 473-80.

[95] Navath RS, Kurtoglu YE, Wang B, Kannan S, Romero R, Kannan RM. Dendrimer-drug conjugates for tailored intracellular drug release based on glutathione levels. Bioconjug Chem 2008; 19: 244655 .

[96] Vandamme TF, Brobeck L. Poly(amidoamine) dendrimers as ophthalmic vehicles for ocular delivery of pilocarpine nitrate and tropicamide. J Control Release 2005; 102: 23-38.

[97] Ivanov AE, Nilsson L, Galaev IY, Mattiasson B. Boronatecontaining polymers form affinity complexes with mucin and enable tight and reversible occlusion of mucosal lumen by poly(vinyl alcohol) gel. Int J Pharm 2008; 358: 36-43.

[98] Ladmiral V, Mantovani G, Clarkson GJ, Cauet S, Irwin JL, Haddleton DM. Synthesis of neoglycopolymers by a combination of "click chemistry" and living radical polymerization. J Am Chem Soc 2006; 128: 4823-30.

[99] Rihova B, Rathi RC, Kopeckova P, Kopecek J. Bioadhesive polymers for oral drug delivery. Adv Exp Med Biol 1995; 371B: 14914.

[100] Watanabe J, Yakou S, Takayama K, Machida Y, Nagai T. Drug release behaviors from hydrogel prepared with water soluble dietary fibers. J Pharm Sci Techn Jpn 1991; 51: 29-35.

[101] Shojaei AH, Zhuo SL, Li X. Transbuccal delivery of acyclovir (II): feasibility, system design, and in vitro permeation studies. J Pharm Pharm Sci 1998; 1: 66-73.

[102] Ceschel GC, Maffei P, Lombardi Borgia S, Ronchi C. Design and evaluation of buccal adhesive hydrocortisone acetate (HCA) tablets. Drug Deliv 2001; 8: 161-71.

[103] Ikinci G, Senel S, Wilson CG, Sumnu M. Development of a buccal bioadhesive nicotine tablet formulation for smoking cessation. Int $\mathrm{J}$ Pharm 2004; 277: 173-8.

[104] Shojaei AH, Li X. Novel copolymers of acrylic acid and poly ethylene glycol monomethylether monomethacrylate for bccal mucoadhesion: Preparation and surface characterization. Pharm Res 1995; 12: S210.

[105] Shojaei AH, Paulson J, Honary S. Evaluation of poly(acrylic acidco-ethylhexyl acrylate) films for mucoadhesive transbuccal drug delivery: factors affecting the force of mucoadhesion. J Control Release 2000; 67: 223-32.

[106] Varshosaz J, Dehghan Z. Development and characterization of buccoadhesive nifedipine tablets. Eur J Pharm Biopharm 2002; 54: 135-41.

[107] Akbari J, Nokhodchi A, Farid D, Adrangui M, Siahi-Shadbad MR, Saeedi M. Development and evaluation of buccoadhesive propranolol hydrochloride tablet formulations: effect of fillers. Farmaco 2004; 59: 155-61.

[108] Desai D, Rinaldi F, Kothari S, et al. Effect of hydroxypropyl cellulose (HPC) on dissolution rate of hydrochlorothiazide tablets. Int J Pharm 2006; 308: 40-5.

[109] Giannola LI, De Caro V, Giandalia G, et al. Diffusion of naltrexone across reconstituted human oral epithelium and histomorphological features. Eur J Pharm Biopharm 2007; 65: 238-46.

[110] Carlo Ceschel G, Bergamante V, Calabrese V, Biserni S, Ronchi C, Fini A. Design and evaluation in vitro of controlled release mucoadhesive tablets containing chlorhexidine. Drug Dev Ind Pharm 2006; 32: 53-61.

[111] Llabot JM, Manzo RH, Allemandi DA. Double-layered mucoadhesive tablets containing nystatin. AAPS Pharm Sci Tech 2002; 3: E22.

[112] Shanker G, Kumar CK, Gonugunta CS, Kumar BV, Veerareddy PR. Formulation and evaluation of bioadhesive buccal drug delivery of tizanidine hydrochloride tablets. AAPS Pharm Sci Tech 2009; 10: 530-9.

[113] Vazquez JA, Patton LL, Epstein JB, et al. Randomized, comparative, double-blind, double-dummy, multicenter trial of miconazole buccal tablet and clotrimazole troches for the treatment of oropharyngeal candidiasis: study of miconazole Lauriad(R) efficacy and safety (SMiLES). HIV Clin Trials 2010; 11: 186-96. 
[114] Cilurzo F, Gennari CG, Selmin F, et al. A new mucoadhesive dosage form for the management of oral lichen planus: formulation study and clinical study. Eur J Pharm Biopharm 2010; 76: 437-42.

[115] Nakane S, Kakumoto M, Yukimatsu K, Chien YW. Oramucosal delivery of LHRH: pharmacokinetic studies of controlled and enhanced transmucosal permeation. Pharm Dev Technol 1996; 1: 251-9.

[116] Park CR, Munday DL. Development and evaluation of a biphasic buccal adhesive tablet for nicotine replacement therapy. Int $\mathbf{J}$ Pharm 2002; 237: 215-26.

[117] Rathbone MJ, Eds. Oral Mucosal Drug Delivery. New York: Mercel Dekker, Inc. 1996.

[118] Beyssac E, Touaref F, Meyer M, Jacob L, Sandouk P, Aiache JM. Bioavailability of morphine after administration of a new bioadhesive buccal tablet. Biopharm Drug Dispos 1998; 19: 401-5.

[119] Ikinci G, Capan Y, Senel S, Alaaddinoglu E, Dalkara T, Hincal AA. In vitrolin vivo studies on a buccal bioadhesive tablet formulation of carbamazepine. Pharmazie 2000; 55: 762-5.

[120] Benes L, Claustrat B, Horriere F, et al. Transmucosal, oral controlled-release, and transdermal drug administration in human subjects: a crossover study with melatonin. J Pharm Sci 1997; 86: 1115-9.

[121] Guggi D, Bernkop-Schnurch A. In vitro evaluation of polymeric excipients protecting calcitonin against degradation by intestinal serine proteases. Int J Pharm 2003; 252: 187-96.

[122] Guggi D, Kast CE, Bernkop-Schnurch A. In vivo evaluation of an oral salmon calcitonin-delivery system based on a thiolated chitosan carrier matrix. Pharm Res 2003; 20: 1989-94.

[123] Guggi D, Krauland AH, Bernkop-Schnurch A. Systemic peptide delivery via the stomach: in vivo evaluation of an oral dosage form for salmon calcitonin. J Control Release 2003; 92: 125-35.

[124] Senel S, Ikinci G, Kas S, Yousefi-Rad A, Sargon MF, Hincal AA. Chitosan films and hydrogels of chlorhexidine gluconate for oral mucosal delivery. Int J Pharm 2000; 193: 197-203.

[125] Guo JH, Cooklock KM. The effects of backing materials and multilayered systems on the characteristics of bioadhesive buccal patches. J Pharm Pharmacol 1996; 48: 255-7.

[126] Li C, Bhatt PP, Johnston TP. Evaluation of a mucoadhesive buccal patch for delivery of peptides: in vitro screening of bioadhesion. Drug Dev Ind Pharm 1998; 24: 919-26.

[127] Guo JH. Investigating the surface properties and bioadhesion of buccal patches. J Pharm Pharmacol 1994; 46: 647-50.

[128] Ishida M, Machida Y, Nambu N, Nagai T. New mucosal dosage form of insulin. Chem Pharm Bull (Tokyo) 1981; 29: 810-6.

[129] Anders R, Merkle HP, Schurr W, Ziegler R. Buccal absorption of protirelin: an effective way to stimulate thyrotropin and prolactin. $\mathrm{J}$ Pharm Sci 1983; 72: 1481-3.

[130] Robinson JR, Longer MA, Veillard M. Bioadhesive polymers for controlled drug delivery. Ann N Y Acad Sci 1987; 507: 307-14.

[131] Eaimtrakarn S, Rama Prasad YV, Puthli SP, Yoshikawa Y, Shibata N, Takada K. Possibility of a patch system as a new oral delivery system. Int J Pharm 2003; 250: 111-7.

[132] Stecker SS, Swift JQ, Hodges JS, Erickson PR. Should a mucoadhesive patch (DentiPatch) be used for gingival anesthesia in children? Anesth Prog 2002; 49: 3-8.

[133] Donnelly RF, McCarron PA, Zawislak AA, Woolfson AD. Design and physicochemical characterisation of a bioadhesive patch for dose-controlled topical delivery of imiquimod. Int J Pharm 2006; 307: 318-25.

[134] Malik IA, Moid I, Haq S, Sabih M. A double-blind, placebocontrolled, randomized trial to evaluate the role of tetrachlorodecaoxide in the management of chemotherapy-induced oral mucositis. J Pain Symptom Manage 1997; 14: 82-7.

[135] Shemer A, Amichai B, Trau H, Nathansohn N, Mizrahi B, Domb AJ. Efficacy of a mucoadhesive patch compared with an oral solu- tion for treatment of aphthous stomatitis. Drugs R D 2008; 9: 2935 .

[136] Ali J, Khar R, Ahuja A, Kalra R. Buccoadhesive erodible disk for treatment of oro-dental infections: design and characterisation. Int $\mathrm{J}$ Pharm 2002; 238: 93-103.

[137] Meng W, Dong Y, Liu J, et al. A clinical evaluation of amlexanox oral adhesive pellicles in the treatment of recurrent aphthous stomatitis and comparison with amlexanox oral tablets: a randomized, placebo controlled, blinded, multicenter clinical trial. Trials 2009; 10: 30

[138] Wong CF, Yuen KH, Peh KK. An in-vitro method for buccal adhesion studies: importance of instrument variables. Int J Pharm 1999; 180: 47-57.

[139] Needleman IG, Martin GP, Smales FC. Characterisation of bioad hesives for periodontal and oral mucosal drug delivery. J Clin Periodontol 1998; 25: 74-82.

[140] Bansal K, Rawat MK, Jain A, Rajput A, Chaturvedi TP, Singh S. Development of satranidazole mucoadhesive gel for the treatment of periodontitis. AAPS Pharm Sci Tech 2009; 10: 716-23.

[141] Vinholis AH, Figueiredo LC, Marcantonio Junior E, Marcantonio RA, Salvador SL, Goissis G. Subgingival utilization of a $1 \%$ chlorhexidine collagen gel for the treatment of periodontal pockets. A clinical and microbiological study. Braz Dent J 2001; 12: 209-13.

[142] Skulason S, Holbrook WP, Kristmundsdottir T. Clinical assessment of the effect of a matrix metalloproteinase inhibitor on aphthous ulcers. Acta Odontol Scand 2009; 67: 25-9.

[143] Favia G, Mariggio MA, Maiorano F, Cassano A, Capodiferro S, Ribatti D. Accelerated wound healing of oral soft tissues and angiogenic effect induced by a pool of aminoacids combined to sodium hyaluronate (AMINOGAM). J Biol Regul Homeost Agents 2008; 22: 109-16.

[144] Campisi G, Giandalia G, De Caro V, Di Liberto C, Arico P, Giannola LI. A new delivery system of clobetasol-17-propionate (lipidloaded microspheres $0.025 \%$ ) compared with a conventional formulation (lipophilic ointment in a hydrophilic phase $0.025 \%$ ) in topical treatment of atrophic/erosive oral lichen planus. A Phase IV, randomized, observer-blinded, parallel group clinical trial. $\mathrm{Br} \mathbf{J}$ Dermatol 2004; 150: 984-90.

[145] Sankar V, Hearnden V, Hull K, et al. Local drug delivery for oral mucosal diseases: challenges and opportunities. Oral Dis $2011 ; 17$ (Suppl 1): 73-84

[146] Colella G, Cannavale R, Vicidomini A, Rinaldi G, Compilato D, Campisi G. Efficacy of a spray compound containing a pool of collagen precursor synthetic aminoacids (1-proline, 1-leucine, 1-lysine and glycine) combined with sodium hyaluronate to manage chemo/radiotherapy-induced oral mucositis: preliminary data of an open trial. Int J Immunopathol Pharmacol 2010; 23: 143-51

[147] Guevara-Aguirre J, Guevara M, Saavedra J, Mihic M, Modi P. Oral spray insulin in treatment of type 2 diabetes: a comparison of efficacy of the oral spray insulin (Oralin) with subcutaneous (SC) insulin injection, a proof of concept study. Diabetes Metab Res Rev 2004; 20: 472-8.

[148] Svensson O, Arnebrant T. Adsorption of serum albumin on silica-the influence of surface cleaning procedures. J Colloid Interface Sc 2010; 344: 44-7.

[149] Kockisch S, Rees GD, Young SA, Tsibouklis J, Smart JD. A directstaining method to evaluate the mucoadhesion of polymers from aqueous dispersion. J Control Release 2001; 77: 1-6.

[150] Park K, Robinson J. Bioadhesive polymers as platforms for oralcontrolled drug delivery: method to study bioadhesion. Int J Pharm 1984; 19: 107-27.

[151] Park H, Robinson JR. Mechanisms of mucoadhesion of poly (acrylic acid) hydrogels. Pharm Res 1987; 4: 457-64. 